\title{
Avaliação de modelos de índices adaptativos para uso no projeto arquitetônico bioclimático
}

\author{
Avaliation of adaptive indexes for applying at the \\ bioclimatic architectural project
}

\section{Iraci Miranda Pereira \\ Eleonora Sad de Assis}

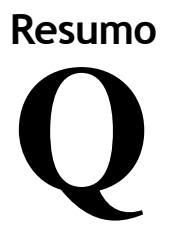

ual modelo de índice adaptativo é adequado para uso no Brasil, sendo capaz de refletir a condição de aclimatação da população em seus resultados? Este trabalho tem por objetivo a identificação de um índice de conforto adaptativo adequado às diferentes condições climáticas existentes no país e que possa ser utilizado nas etapas iniciais de projeto. A metodologia adotada neste trabalho é a comparação entre quatro diferentes índices de conforto adaptativo, com os parâmetros de conforto térmico definidos por estudos regionais brasileiros de conforto térmico e de seu uso para diferentes condições climáticas. Além disso, os quatro modelos são utilizados como ferramenta de projeto no dimensionamento de dispositivos de proteção solar em diferentes cidades brasileiras, sendo o desempenho dos dispositivos avaliado por meio de simulação computacional. O resultado é a seleção de um índice e de uma faixa de conforto com melhor resposta para as diferentes condições climáticas brasileiras. Observou-se que esses índices são ferramentas importantes no projeto bioclimático, mas seu uso na avaliação do conforto ambiental dos usuários possui limitações.

Iraci Miranda Pereira Escola de Arquitetura Universidade Federal de Minas Gerais Rua Paraíba, 697, Funcionários Belo Horizonte - MG - Brasi CEP 30130-140 Tel.: (31) 3409-1825 E-mail: iraci.pereira@ymail.com

Eleonora Sad de Assis Escola de Arquitetura Universidade Federal de Minas Gerais Rua Paraíba, 697, Funcionários Belo Horizonte - MG - Brasil CEP 30130-140 Tel.: (31) 3409-1825 E-mail: eleonorasad@yahoo.com.br

Recebido em 16/10/08 Aceito em 11/02/09
Palavras-chave: Índices adaptativos. Análise comparada. Aplicação em projeto.

\section{Abstract}

What kind of adaptive index is suitable for use in Brazil, being able to reflect the condition of acclimatization of the population in its results? This work has as objective the identification of an adaptive thermal comfort index adjusted to different existing climatic conditions in Brazil that can be used at the initial stages of the building project. The methodology adopted in this work is the comparison among four different adaptive indices and those ones validated by regional Brazilian studies in different climatic regions. Moreover, the four adaptive models were used as project tools when designing solar devices in different Brazilian cities. The performance of the devices was evaluated by means of computational simulation. The result was the selection of an index and range of comfort better sensitive to the different Brazilian climatic conditions. We found out that these indices are important tools in bioclimatic design, but its use in assessing the environmental comfort of the users has limitations.

Keywords: Adaptive indices. Comparative assessment. Building project applications. 


\section{Introdução}

Atualmente, no Brasil, estão em discussão várias regulamentações e selos de eficiência energética e/ou de sustentabilidade de edificações. Nesses trabalhos, a avaliação do desempenho da edificação em termos de conforto do usuário baseia-se em normas internacionais, como a ASHRAE Standart 55 e a ISO 7730. Com exceção da primeira, as normas geralmente baseiam-se no modelo do Voto Médio Predito (PMV), desenvolvido por Fanger. Como mostrado por vários autores (BRAGER; DEDEAR, 1998; DEDEAR; BRAGER, 2002; FANGER; TOFUM, 2002; NICOL, 2004), inclusive em estudos brasileiros (ARAÚJO, 1996; GONÇALVES, 2000), o PMV não é capaz de estimar a real sensação de conforto térmico de indivíduos aclimatados a climas tropicais, condição predominante no território brasileiro, prevendo sensação de desconforto térmico mais severa do que os usuários realmente percebem.

Como alternativa ao uso do PMV, alguns autores brasileiros têm adotado diferentes índices adaptativos. Esses índices caracterizam-se por sua simplicidade: de modo geral, apresentam apenas uma temperatura de conforto térmico em função da temperatura média mensal registrada. Por esse motivo, servem como modelo exploratório nas etapas iniciais do projeto arquitetônico, nas quais o projetista possui poucos dados e necessita de informações objetivas para direcionar as estratégias que adotará. Contudo, não existe consenso sobre qual índice adaptativo usar, visto que existem vários modelos desenvolvidos no mundo, mas nenhum modelo desenvolvido ou validado para o país.

Diante desse problema, o presente trabalho discute a aplicação de índices adaptativos em diferentes condições climáticas brasileiras, visando à busca de um modelo que possa servir como critério de escolha de soluções projetuais do desenho bioclimático, nas etapas iniciais de projeto, e que seja sensível às condições climáticas nacionais e de aclimatação da população.

Para a seleção do índice, o procedimento adotado é a comparação dos resultados obtidos por cada modelo adaptativo com os parâmetros de conforto térmico definidos em estudos desenvolvidos em território nacional. Visto que os modelos adaptativos utilizam dados de temperatura do ar exterior no cálculo da temperatura de conforto, este trabalho baseia suas comparações nos resultados obtidos com a aplicação dos dados das Normais Climatológicas, pois eles são internacionalmente aceitos e disponíveis para inúmeras localidades brasileiras. A última avaliação realizada neste trabalho é a comparação do uso desses índices como ferramentas do projeto bioclimático, por meio de simulação computacional.

Os estudos adotados como base de referência são os de Araújo (1996), que estabeleceu uma zona de conforto para Natal, Xavier (1999), para Florianópolis, e Gonçalves (2000), para Belo Horizonte. Essas são as localidades escolhidas para comparação neste trabalho, excetuando-se Natal, pois não há dados climáticos normais para esta cidade. Assim, os parâmetros definidos por Araújo (1996) são comparados com resultados obtidos para Fortaleza, porque, de acordo com a autora, a zona de conforto definida para Natal pode ser expandida a outras cidades de clima tropical úmido do litoral nordestino.

A estrutura deste artigo apresenta, em cada item, uma das etapas realizadas de análise dos modelos adaptativos. Assim, no próximo item Índices de conforto térmico, foi feita uma revisão dos modelos adaptativos existentes que atendem aos objetivos deste trabalho, além dos trabalhos desenvolvidos em território nacional sobre índices de conforto térmico.

Em Comparação dos índices adaptativos com os estudos brasileiros e Avaliação dos resultados dos índices adaptativos para diferentes condições climáticas brasileiras realiza-se a comparação dos resultados das zonas de conforto térmico dos índices adaptativos com as zonas obtidas nos estudos nacionais. Nessa etapa, são estudadas as cidades para as quais há zonas de conforto definidas, em conjunto com aquelas onde ocorreram as maiores amplitudes térmicas, para observar a variação da zona de conforto em condições de temperaturas mais extremas.

No item Estudo de caso, os índices adaptativos são usados como parâmetro projetual no dimensionamento de dispositivos de proteção solar para o caso de estudo de uma sala comercial. A avaliação do método é feita por meio da simulação de desempenho térmico da sala com as diferentes soluções de dispositivos de proteção encontrados com a aplicação dos vários índices.

Por fim, os resultados do desempenho térmico dos casos simulados são apresentados e discutidos em Resultados da simulação. Em Conclusões apresenta-se os limites do trabalho e as considerações finais. 


\section{Índices de conforto térmico}

Os índices de conforto térmico integram as variáveis do microclima de um dado volume de ar às respostas de adaptação humana, em condições de repouso ou no exercício de atividades variadas, de maneira a identificar condições psicrométricas de conforto e/ou desconforto higrotérmico para uma população aclimatada.

Focalizam-se aqui dois grupos de índices de conforto, os adaptativos e os trabalhos em campo sobre conforto térmico realizados no Brasil, com o intuito de validação, para regiões ou localidades específicas, de modelos que se baseiam no balanço térmico do corpo humano. No caso dos índices adaptativos, são utilizados neste trabalho modelos para ambientes internos de edifícios não climatizados e cuja temperatura de conforto esteja relacionada apenas à temperatura média do ar exterior.

\section{Abordagem adaptativa}

Esses índices baseiam-se em resultados de trabalhos de campo que medem as condições ambientais e a resposta simultânea de sensação térmica em indivíduos envolvidos em suas tarefas habituais, com a menor intervenção possível dos pesquisadores. Dessa forma, os índices adaptativos buscam reproduzir as condições reais, nas quais o indivíduo também é agente nas condições térmicas do ambiente, ao interagir com o meio.

Os modelos aqui apresentados são:

(a) a equação desenvolvida por Aluciems (1981), citada por Brager e DeDear (1998);

(b) a equação de Humphreys (1978) ${ }^{1}$, citada por Nicol (2004) e desenvolvida a partir de estudos de campo no Reino Unido, Índia, Iraque, Singapura e Europa;

(c) a temperatura neutra de conforto de Nicol e Humphreys (2002), ajustada a partir da base de dados da ASHRAE; e

(d) o modelo adaptativo de DeDear e Brager (2002), proposto como alternativa para o método da ASHRAE Standart 55 de 1998 e incorporado na versão de 2004.

As equações para a determinação da temperatura de neutralidade propostas por esses autores são apresentadas no Quadro 1, assim como a faixa de conforto térmico definida a partir da temperatura neutra.

\section{Abordagem do balanço térmico humano}

Esses modelos veem as pessoas como receptores do estímulo térmico e pressupõem que os efeitos de um ambiente térmico na sensação de conforto são mediados apenas por trocas de calor e massa entre o corpo humano e o meio (BRAGER; DEDEAR, 1998). São baseados em experimentos laboratoriais extensivos e rigorosos, que buscam estabelecer relações causais entre o comportamento das variáveis ambientais, como temperatura e umidade do ar, com a resposta subjetiva de sensação de conforto térmico. Frequentemente esses modelos são validados também por estudos de campo.

\section{Estudos brasileiros}

Os trabalhos brasileiros utilizados como base de referência são investigações em campo sobre o conforto térmico de usuários em ambientes interiores. Em comum, têm os objetivos, a definição de parâmetros de conforto térmico para populações aclimatadas brasileiras e a metodologia, em trabalhos de campo em escolas do $2^{\circ}$ grau, em Natal (ARAÚJO, 1996), Florianópolis (XAVIER, 1999) e Belo Horizonte (GONÇALVES, 2000). Geraram dados para a avaliação da adequação de determinados índices de conforto, geralmente baseados em modelos de balanço térmico, às regiões e/ou localidades em que são aplicados.

Os parâmetros de conforto térmico encontrados pelos três autores são sintetizados no Quadro 2. Esses valores são tomados como referência neste artigo, sendo considerados representativos da faixa de conforto térmico de indivíduos aclimatados.

As zonas de conforto térmico definidas pelos autores a partir desses parâmetros, para Natal, Florianópolis e Belo Horizonte, plotadas sobre as respectivas cartas psicrométricas, são apresentadas na Figura 1, na qual também está inserida a zona de conforto térmico definida por Givoni (1998), para permitir comparação.

Observa-se que as zonas definidas por Xavier (1999) e Gonçalves (2000) são as que possuem maior aproximação entre si e com o diagrama de Givoni (1998), sendo a determinada por Gonçalves mais restritiva. A zona definida por Araújo (1996) não possui nenhuma região em comum com as dos outros autores brasileiros e localiza-se, principalmente, na zona de influência da ventilação definida por Givoni (1998).

${ }^{1}$ HUMPHREYS, M. Outdoor Temperatures and Comfort Indoors. Building Research \& Information, v. 6, n. 2, p. 92, 1978. 


\begin{tabular}{|l|l|l|}
\hline \multicolumn{1}{|c|}{ Autores } & \multicolumn{1}{|c|}{ Equação } & \multicolumn{1}{c|}{ Faixa de conforto } \\
\hline Aluciems (1981) & $\mathrm{T}_{\mathrm{n}}=0,314 . \mathrm{T}+17,6^{\circ} \mathrm{C}$ & Sem definição \\
\hline Humphreys (1978) & $\mathrm{T}_{\mathrm{n}}=0,534 . \mathrm{T}+12,9^{\circ} \mathrm{C}$ & $\begin{array}{l}\mathrm{T}_{\mathrm{n}} \pm 2 \text { a } 3{ }^{\circ} \mathrm{C} \text { e em condições de umidade relativa elevada, } \mathrm{T}_{\mathrm{n}} \pm \\
1{ }^{\circ} \mathrm{C}\end{array}$ \\
\hline $\begin{array}{l}\text { Nicol e Humphreys } \\
(2002)\end{array}$ & $\mathrm{T}_{\mathrm{n}}=0,540 . \mathrm{T}+13,5^{\circ} \mathrm{C}$ & $\begin{array}{l}\mathrm{T}_{\mathrm{n}} \pm 2{ }^{\circ} \mathrm{C} \text { em situações onde não há possibilidades de mudança } \\
\text { de vestimenta, nível de atividade ou taxa de ventilação }\end{array}$ \\
\hline De Dear e Brager (2002) & $\mathrm{T}_{\mathrm{n}}=0,310 . \mathrm{T}+17,8^{\circ} \mathrm{C}$ & $\begin{array}{l}\mathrm{T}_{\mathrm{n}} \pm 2,5^{\circ} \mathrm{C}(90 \% \text { de aceitabilidade }) \text { e } \mathrm{T}_{\mathrm{n}} \pm 3,5^{\circ} \mathrm{C}(80 \% \text { de } \\
\text { aceitabilidade })\end{array}$ \\
\hline
\end{tabular}

Legenda:

Tn: temperatura de conforto ou de neutralidade;

Tn: temperatura média mensal externa.

Quadro 1 - Equações para cálculo da temperatura neutra

\begin{tabular}{|l|c|c|c|}
\hline \multirow{2}{*}{\multicolumn{1}{|c|}{ Variável }} & \multicolumn{3}{c|}{ Limites de conforto } \\
\cline { 2 - 4 } & Natal & Florianópolis & Belo Horizonte \\
\hline Temperatura do ar & $25,1-28,1^{\circ} \mathrm{C}$ & $19,90-25,8^{\circ} \mathrm{C}$ & $20,8-24,7^{\circ} \mathrm{C}$ \\
\hline Temperatura radiante média & $25,9-29,2^{\circ} \mathrm{C}$ & & \\
\hline Temperatura operativa $^{2}$ & $25,5-28,8^{\circ} \mathrm{C}$ & $20,0-26,0^{\circ} \mathrm{C}$ & $21,1-24,9{ }^{\circ} \mathrm{C}$ \\
\hline Umidade relativa $^{*}$ & $69 \%-92 \%$ & & $64 \%-93 \%$ \\
\hline Velocidade do ar & $0,12-0,83 \mathrm{~m} / \mathrm{s}$ & & $0,40-1,70 \mathrm{~m} / \mathrm{s}$ \\
\hline
\end{tabular}

Fontes: Araújo (1996), Xavier (1999) e Gonçalves (2000).

Quadro 2 - Parâmetros de conforto térmico para Natal, Florianópolis e Belo Horizonte

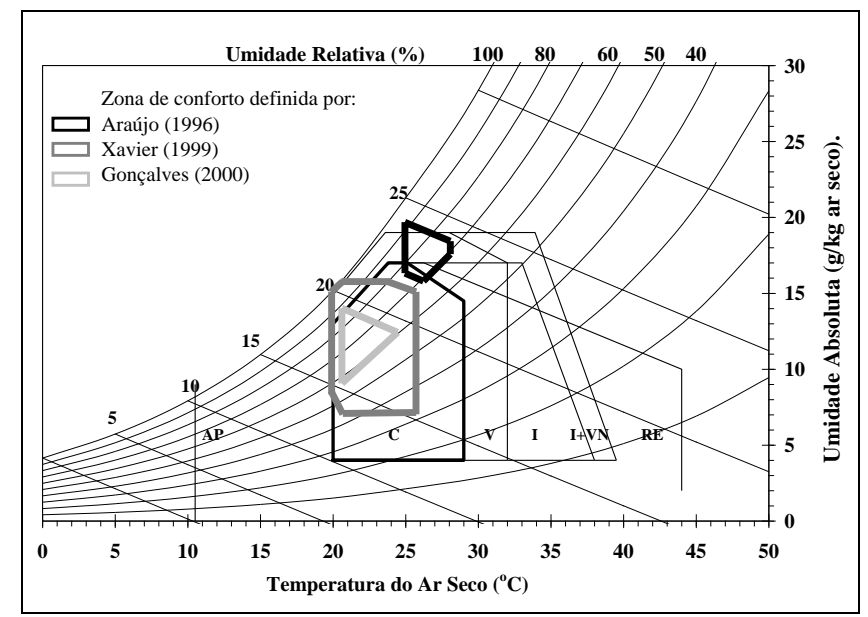

Figura 1 - Zonas de conforto térmico definida por Araújo (1996) e Xavier (1999), Gonçalves (2000) e Givoni (1998) e plotados sobre carta psicrométrica

\section{Comparação dos índices adaptativos com os estudos brasileiros}

Os dados de temperatura média mensal, extraídos das Normais Climatológicas (BRASIL, 1992), foram inseridos nos modelos de Auliciems (1981),
Humphreys (1978), Nicol e Humphreys (2002) e DeDear e Brager (2002) para as cidades de Fortaleza, Florianópolis e Belo Horizonte. Os valores obtidos de temperatura neutra mensal são comparados com as temperaturas-limite de conforto definidos por Araújo (1996) (Figura 2), por Xavier (1999) (Figura 3) e por Gonçalves (2000) (Figura 4).

\footnotetext{
${ }^{2}$ Temperatura operativa: considerada como sendo a média aritmética entre a temperatura do ar e a temperatura média radiante, em ${ }^{\circ} \mathrm{C}$.
} 


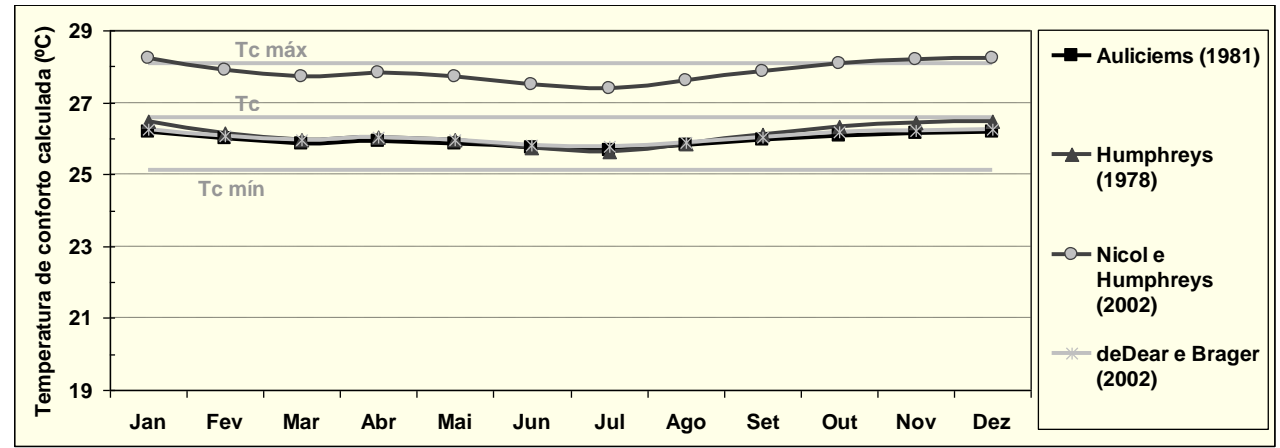

Fonte: Araújo (1996)

Figura 2 - Temperatura neutra mensal calculada para Fortaleza por diferentes índices adaptativos. Temperaturas de conforto (Tc). Limite da zona de conforto segundo Araújo.

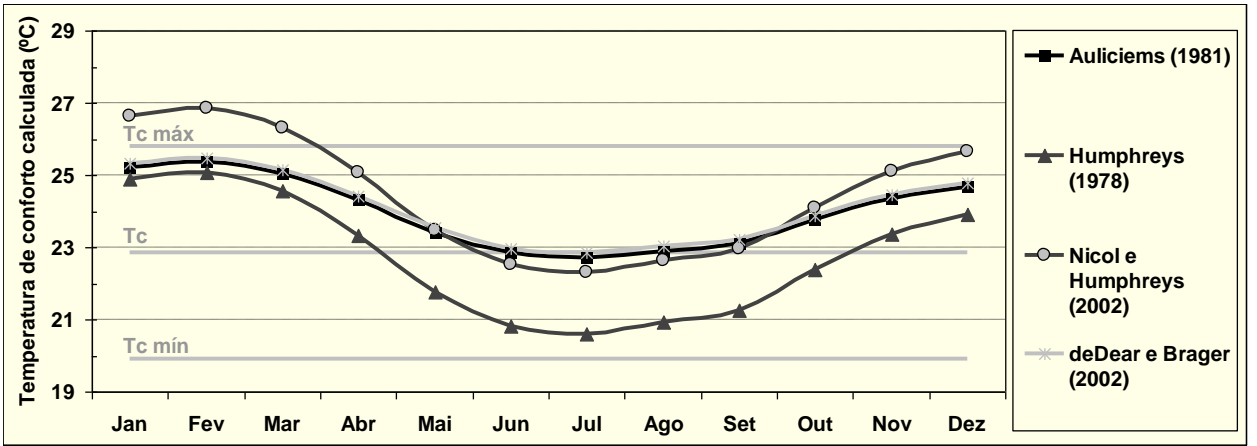

Fonte: Xavier (1999)

Figura3 - Temperatura neutra mensal calculada para Florianópolis por diferentes índices adaptativos. Temperaturas de conforto (Tc). Limite da zona de conforto segundo Xavier.

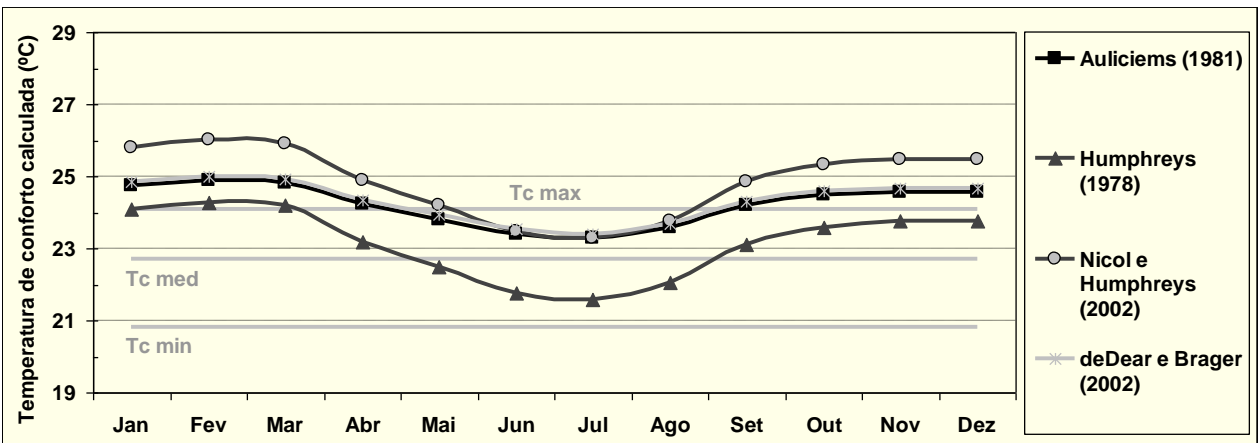

Fonte: Gonçalves (2000)

Figura 4 - Temperatura neutra mensal calculada para Belo Horizonte por diferentes índices adaptativos. Temperaturas de conforto (Tc). Limite da zona de conforto segundo Gonçalves

Observa-se que a curva obtida pela equação de Humphreys (1978) é a que mais se aproxima da faixa de conforto local para as três cidades. A curva obtida pela equação de Nicol e Humphreys (2002) é a que mais se afasta da faixa de conforto local em todos os casos, apresentando valores de temperatura neutra sempre mais elevados que os dos demais modelos. As curvas obtidas pelos modelos de Auliciems (1981) e DeDear e Brager (2002) têm diferença de apenas $0,1{ }^{\circ} \mathrm{C}$, o que é esperado por serem as equações parecidas. Com menor amplitude de variação que as curvas de Humphreys (1978) e Nicol e Humphreys (2002), elas possuem razoável aproximação da temperatura de conforto obtida para Fortaleza e Belo Horizonte, porém, no caso de Florianópolis, só se enquadram nos limites de conforto no período de inverno.

Desse modo, observa-se que, aparentemente, o modelo de Humphreys (1978) seria o mais adequado para uma abordagem geral do território nacional. Para avaliar se tal premissa é mesmo aceitável, no próximo item apresenta-se um teste com dados horários de temperatura para as três cidades e para outras localidades do país que 
possuem características climáticas extremas. Isso foi feito porque as diferentes equações podem fornecer valores muito distintos de temperatura neutra em climas que possuem maior amplitude térmica. Assim, pode-se verificar se, mesmo sob essas condições mais extremas, as zonas de conforto geradas pela aplicação dos índices adaptativos assemelham-se aos valores encontrados pelos autores brasileiros.

\section{Avaliação dos resultados dos índices adaptativos para diferentes condições climáticas brasileiras}

Os dados horários médios mensais de temperatura do ar foram obtidos a partir das temperaturas do ar máxima e mínima mensais, dadas nas Normais Climatológicas, pelo ajuste dos dados locais à curva padrão da Organização Mundial de Meteorologia, conforme procedimento mostrado em Assis (2001). A temperatura de conforto térmico, ou neutra, é determinada utilizando-se as equações descritas no item Abordagem adaptativa, assim como as faixas de conforto térmico: a partir da temperatura neutra mensal (Tn), somando-se ou subtraindo-se $2{ }^{\circ} \mathrm{C}$ (HUMPHREYS, 1978; NICOL; HUMPHREYS, 2002) ou 2,5 ${ }^{\circ} \mathrm{C}$ (DEDEAR; BRAGER, 2002). São definidas também zonas de leve desconforto térmico por calor e frio, somando-se ou subtraindo-se $4{ }^{\circ} \mathrm{C}$ (NICOL; HUMPHREYS, 2002; HUMPHREYS, 1978) ou $3,5^{\circ} \mathrm{C}$ (DEDEAR; BRAGER, 2002). O valor de 4 ${ }^{\circ} \mathrm{C}$ é tomado como referência a partir do estudo de Nicol (2004), por não haver esse tipo de limite nos trabalhos originais dos autores considerados.

Como não há definição de zonas de conforto para o modelo de Auliciems (1981), foram adotados os valores de $\pm 2{ }^{\circ} \mathrm{C}$ e $\pm 4{ }^{\circ} \mathrm{C}$ para as zonas de conforto e leve desconforto respectivamente. Dessa forma, pode-se comparar zonas diferentes para valores de temperatura neutra semelhantes.
Essas faixas de conforto térmico são sintetizadas no Quadro 3.

Nos subitens seguintes, são mostrados os resultados obtidos pela utilização dessa classificação para as capitais apresentadas no item anterior e outras três cidades: Conceição do Araguaia, Bambuí e Foz do Iguaçu. Essas últimas foram selecionadas por possuírem grande amplitude térmica anual e estarem em regiões com o mesmo zoneamento bioclimático, e latitude e altitude próximas às cidades dos estudos brasileiros.

\section{Comparação com Araújo (1996): Fortaleza e Conceição do Araguaia}

A classificação dos dados horários de Fortaleza é apresentada na Figura 5 e, para a cidade de Conceição do Araguaia, no Pará (latitude de $8^{\circ} 15^{\prime \prime}$ e altitude de 157 m), na Figura 6 .

Por essas figuras, observam-se resultados semelhantes aos obtidos com os dados médios mensais em Comparação dos índices adaptativos com os estudos brasileiros. As zonas de desconforto geradas por Auliciems (1981), Humphreys (1978) e DeDear e Brager (2002) assemelham-se à zona definida por Araújo (1996), tendo as dos dois primeiros uma aproximação um pouco maior que a faixa obtida por DeDear e Brager (2002).

As zonas encontradas com o índice de Nicol e Humphreys (2002) possuem maior distanciamento da definida por Araújo (1996), indicando limites com temperatura de $1{ }^{\circ} \mathrm{C}$ mais elevados ao longo de todo o ano. Isso produziu maiores períodos de desconforto por frio e menos horários de desconforto por calor, principalmente no caso de Fortaleza. Nessas cidades, observa-se que, para um mesmo modelo adaptativo, a maior amplitude térmica não gera diferenciação no comportamento dos resultados.

Legenda:

\begin{tabular}{|c|c|c|}
\hline Faixa de temperatura & Sensação térmica & Padrão adotado \\
\hline $\mathrm{T}<\mathrm{T}_{\mathrm{n}}-4^{\circ} \mathrm{C}$ & Desconforto por frio & \\
\hline $\mathrm{T}<\mathrm{T}_{\mathrm{n}}-2^{\circ} \mathrm{C}$ & Pouco frio & \\
\hline $\mathrm{T}_{\mathrm{n}}-2^{\circ} \mathrm{C}<\mathrm{T}<\mathrm{T}_{\mathrm{n}}+2{ }^{\circ} \mathrm{C}$ & Zona de conforto & \\
\hline $\mathrm{T}>\mathrm{T}_{\mathrm{n}}+2^{\circ} \mathrm{C}$ & Pouco calor & \\
\hline $\mathrm{T}>\mathrm{T}_{\mathrm{n}}+4{ }^{\circ} \mathrm{C}$ & Desconforto por calor & \\
\hline
\end{tabular}

T: temperatura média mensal horária

Tn: temperatura neutra calculada

Quadro 3 - Valores para classificação da temperatura do ar em função da sensação térmica 


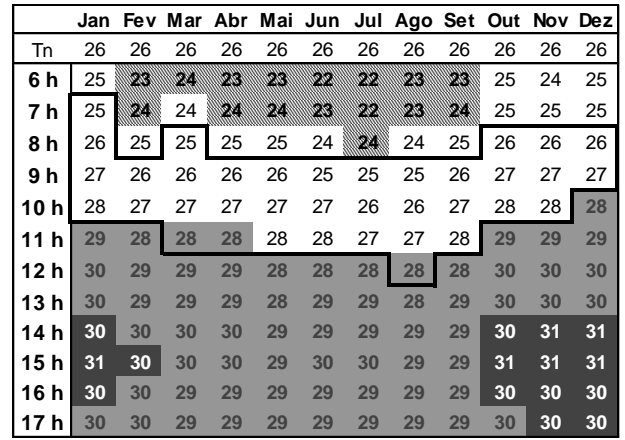

(a) Auliciems (1981)

\begin{tabular}{|c|c|c|c|c|c|c|c|c|c|c|c|c|}
\hline & Jan & $\mathrm{Fev}$ & Mar & $A b r$ & Mai & Jun & Jul & Ago & Set & Out & Nov & Dez \\
\hline$T n$ & 28 & 28 & 28 & 28 & 28 & 27 & 27 & 28 & 28 & 28 & 28 & 28 \\
\hline $6 \mathrm{~h}$ & 25 & 23 & 24 & 23 & 23 & 22 & 22 & 23 & 23 & 25 & 24 & 25 \\
\hline $7 \mathrm{~h}$ & 25 & 24 & 24. & 24 & 24 & 23 & 22 & 23 & 24 & 25 & 25 & 25 \\
\hline $8 \mathrm{~h}$ & 26 & 25 & 25 & 25 & 25 & 24 & 24 & 24 & 25 & 26 & 26 & 26 \\
\hline $9 \mathrm{~h}$ & 27 & 26 & 26 & 26 & 26 & 25 & 25 & 25 & 26 & 27 & 27 & 27 \\
\hline $10 \mathrm{~h}$ & 28 & 27 & 27 & 27 & 27 & 27 & 26 & 26 & 27 & 28 & 28 & 28 \\
\hline $11 \mathrm{~h}$ & 29 & 28 & 28 & 28 & 28 & 28 & 27 & 27 & 28 & 29 & 29 & 29 \\
\hline $12 \mathrm{~h}$ & 30 & 29 & 29 & 29 & 28 & 28 & 28 & 28 & 28 & 30 & 30 & 30 \\
\hline $13 \mathrm{~h}$ & 30 & 29 & 29 & 29 & 28 & 29 & 29 & 28 & 29 & 30 & 30 & 30 \\
\hline $14 \mathrm{~h}$ & 30 & 30 & 30 & 30 & 29 & 29 & 29 & 29 & 29 & 30 & 31 & 31 \\
\hline $15 \mathrm{~h}$ & 31 & 30 & 30 & 30 & 29 & 30 & 30 & 29 & 29 & 31 & 31 & 31 \\
\hline $16 \mathrm{~h}$ & 30 & 30 & 29 & 29 & 29 & 29 & 29 & 29 & 29 & 30 & 30 & 30 \\
\hline $17 \mathrm{~h}$ & 30 & 30 & 29 & 29 & 29 & 29 & 29 & 29 & 29 & 30 & 30 & 30 \\
\hline
\end{tabular}

(c) Nicol e Humphreys (2002)

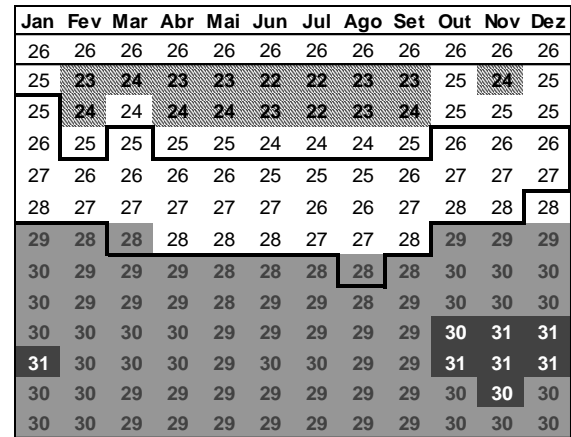

(b) Humphreys (1978)

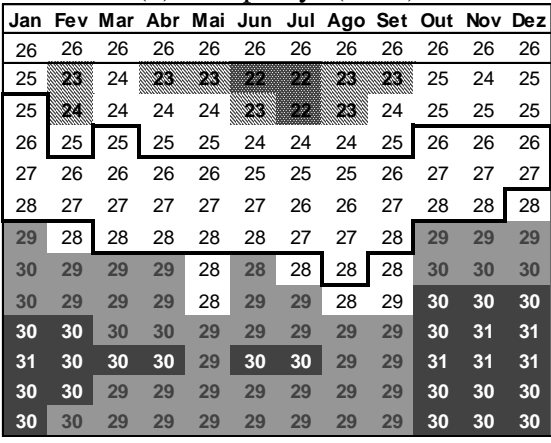

(d) De Dear e Brager (2002)

Zonas de desconforto térmico: Frio Pouco Frio Conforto Pouco calor Calor por Araújo (1996) Figura 5 - Classificação das temperaturas horárias ${ }^{3}$ da cidade de Fortaleza (CE) de acordo com os quatro índices adaptativos

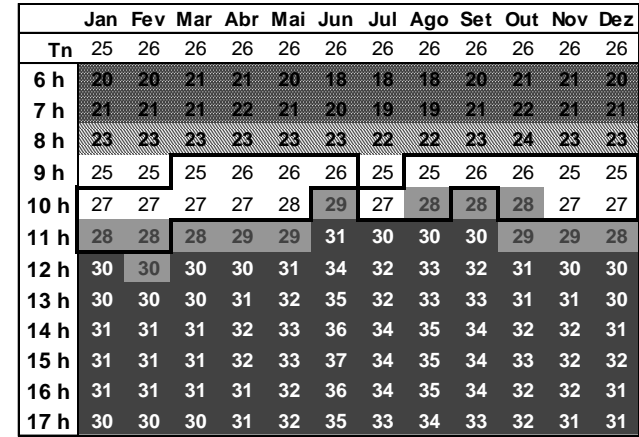

(a) Auliciems (1981)

\begin{tabular}{|c|c|c|c|c|c|c|c|c|c|c|c|c|}
\hline & Jan & Fev & Mar & Abr & Mai & Jun & Jul & Ago & Set & Out & Nov & Dez \\
\hline$T n$ & 27 & 27 & 27 & 27 & 28 & 27 & 27 & 28 & 28 & 28 & 27 & 27 \\
\hline $6 \mathrm{~h}$ & 20 & 20 & 21 & 21 & 20 & 18 & 18 & 18 & 20 & 21 & 21 & 20 \\
\hline $7 \mathrm{~h}$ & 21 & 21 & 21 & 22 & 21 & 20 & 19 & 19 & 21 & 22 & 21 & 21 \\
\hline $8 \mathrm{~h}$ & 23 & 23 & 23 & 23 & 23 & 23 & 22 & 22 & 23 & 24 & 23 & 23 \\
\hline $9 \mathrm{~h}$ & 25 & 25 & 25 & 26 & 26 & 26 & 25 & $\mathbb{2 5}$ & 26 & 26 & 25 & 25 \\
\hline $10 \mathrm{~h}$ & 27 & 27 & 27 & 27 & 28 & 29 & 27 & 28 & 28 & 28 & 27 & 27 \\
\hline $11 \mathrm{~h}$ & 28 & 28 & 28 & 29 & 29 & 31 & 30 & 30 & 30 & 29 & 29 & 28 \\
\hline $12 \mathrm{~h}$ & 30 & 30 & 30 & 30 & 31 & 34 & 32 & 33 & 32 & 31 & 30 & 30 \\
\hline $13 \mathrm{~h}$ & 30 & 30 & 30 & 31 & 32 & 35 & 32 & 33 & 33 & 31 & 31 & 30 \\
\hline $14 \mathrm{~h}$ & 31 & 31 & 31 & 32 & 33 & 36 & 34 & 35 & 34 & 32 & 32 & 31 \\
\hline $15 \mathrm{~h}$ & 31 & 31 & 31 & 32 & 33 & 37 & 34 & 35 & 34 & 33 & 32 & 32 \\
\hline $16 \mathrm{~h}$ & 31 & 31 & 31 & 31 & 32 & 36 & 34 & 35 & 34 & 32 & 32 & 31 \\
\hline $17 \mathrm{~h}$ & 30 & 30 & 30 & 31 & 32 & 35 & 33 & 34 & 33 & 32 & 31 & 31 \\
\hline
\end{tabular}

(c) Nicol e Humphreys (2002)

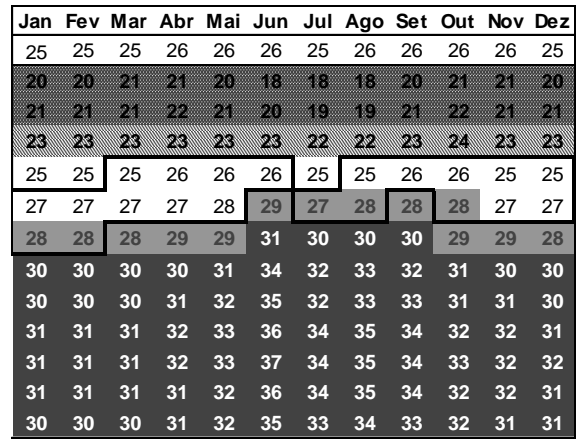

(b) Humphreys (1978)

Jan Fev Mar Abr Mai Jun Jul Ago Set Out Nov Dez

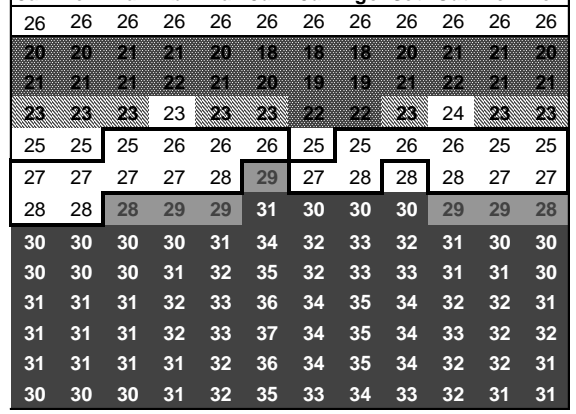

(d) De Dear e Brager (2002)

Zonas de desconforto térmico: Frio Pouco Frio Conforto Pouco calor Calor por Araújo (1996) Figura 6 - Classificação das temperaturas horárias da cidade de Conceição do Araguaia (PA) de acordo com os quatro índices adaptativos

\footnotetext{
${ }^{3}$ Os valores de temperatura neutra e das faixas de conforto foram calculados com precisão de uma casa decimal, sendo apresentados com arredondamento para facilitar a visualização.
} 


\section{Comparação com Xavier (1999): Florianópolis e Foz do Iguaçu (PR)}

A classificação das temperaturas pela sensação térmica dos índices adaptativos é apresentada na Figura 7, para Florianópolis, e na Figura 8, para Foz do Iguaçu (Paraná, 25 $33^{\circ}$ de latitude sul e $154 \mathrm{~m}$ de altitude).

Para os dados mensais, o modelo de Humphreys (1978) é o que apresenta melhor aproximação com a zona definida por Xavier (1999). Isso também é observado nos dados horários de Florianópolis, mas não em Foz de Iguaçu, nos quais há um período mais longo de desconforto por frio. Assim, a maior amplitude térmica da cidade de Foz de Iguaçu influencia os resultados desse modelo, reduzindo sua aproximação com a faixa tomada como referência.

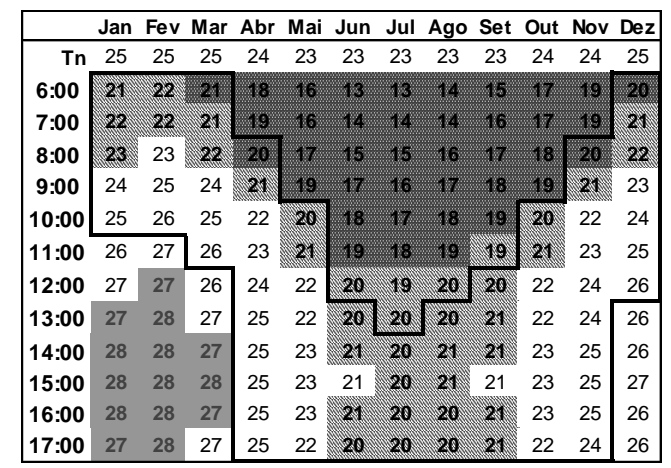

(a) Auliciems (1981)

\begin{tabular}{|c|c|c|c|c|c|c|c|c|c|c|c|c|}
\hline & Jan & $\mathrm{Fev}$ & Mar & Abr & Mai & Jun & Jul & Ago & Set & Out & Nov & Dez \\
\hline $\mathrm{Tn}$ & 27 & 27 & 26 & 25 & 23 & 23 & 22 & 23 & 23 & 24 & 25 & 26 \\
\hline $6: 00$ & 21 & 22 & 21 & 18 & 16 & 13 & 13 & 14 & 15 & 17 & 19 & 20 \\
\hline 7:00 & 22. & 22 & 21 & 19 & 16 & 14 & 14 & 14 & 16 & 17 & 19 & 21 \\
\hline 8:00 & 23 & 23 & 22 & 20 & 17 & 15 & 15 & 16 & 17 & 18 & 20 & 22 \\
\hline 9:00 & 24 & 25 & 24 & 21 & 19 & 17 & 16 & 17 & 18 & 19 & 121 & 23 \\
\hline $10: 00$ & 25 & 26 & 25 & 22 & 20 & 18 & 17 & 18 & 19 & 20 & 22 & 24 \\
\hline 11:00 & 26 & 27 & 26 & 23 & 21 & 19 & 18 & 19 & 19 & 121 & 23 & 25 \\
\hline $12: 00$ & 27 & 27 & 26 & 24 & 22 & 20 & 19 & 20 & 20 & 22 & 24 & 26 \\
\hline $13: 00$ & 27 & 28 & 27 & 25 & 22 & 20 & 20 & 20 & 21 & 22 & 24 & 26 \\
\hline $14: 00$ & 28 & 28 & 27 & 25 & 23 & 21 & 20 & 21 & 21 & 23 & 25 & 26 \\
\hline $15: 00$ & 28 & 28 & 28 & 25 & 23 & 21 & 20 & 21 & 21 & 23 & 25 & 27 \\
\hline $16: 00$ & 28 & 28 & 27 & 25 & 23 & 21 & 20 & 20 & 21 & 23 & 25 & 26 \\
\hline $17: 00$ & 27 & 28 & 27 & 25 & 22 & 20 & 20 & 20 & 21 & 22 & 24 & 26 \\
\hline
\end{tabular}

(c) Nicol e Humphreys (2002)
Os modelos de Auliciems (1981) e DeDear e Brager (2002) apresentam zonas de conforto aproximadas à de Xavier (1999) em ambas as cidades, sendo a aproximação da zona definida para o primeiro modelo um pouco melhor. Novamente, o modelo de Nicol e Humphreys (2002) é o que produz maior zona de desconforto por frio.

\section{Comparação com Gonçalves (2000): Belo Horizonte e Bambuí}

A classificação das temperaturas pela sensação térmica pelos quatro índices adaptativos para Belo Horizonte e Bambuí (latitude de $20^{\circ}$ Sul, altitude de $666 \mathrm{~m}$ ) é mostrada nas Figuras 9 e 10 respectivamente.

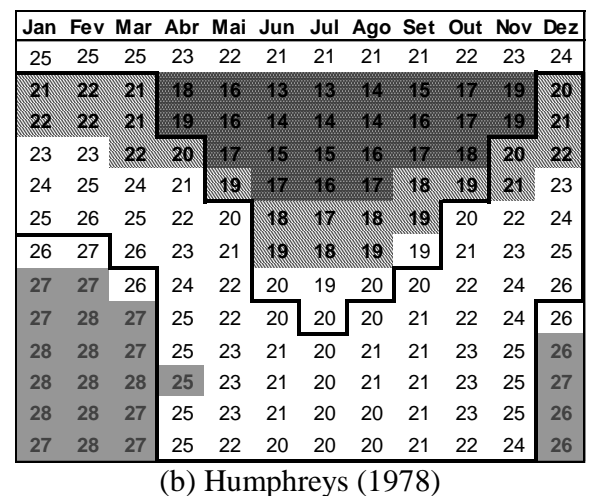

Jan Fev Mar Abr Mai Jun Jul Ago Set Out Nov Dez

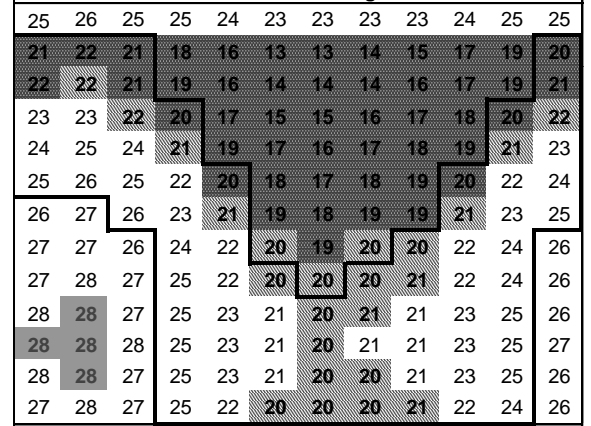

(d) De Dear e Brager (2002)

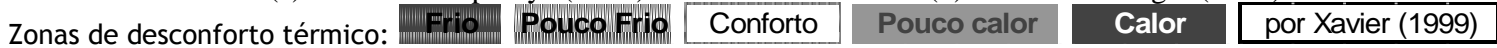

Figura 7- Classificação das temperaturas horárias da cidade de Florianópolis (SC) de acordo com os quatro índices adaptativos 


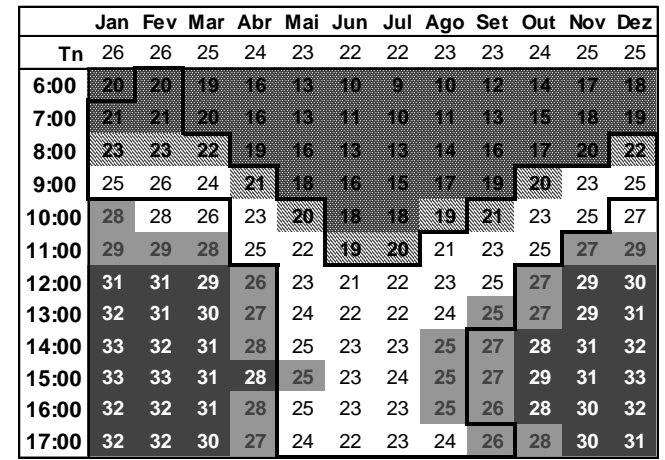

(a) Auliciems (1981)

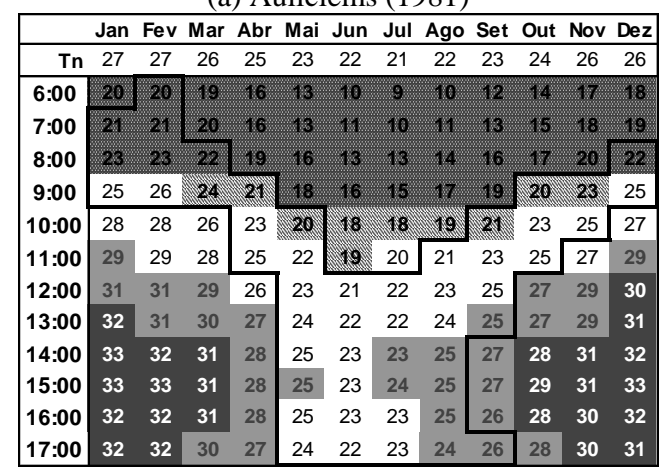

(c) Nicol e Humphreys (2002)

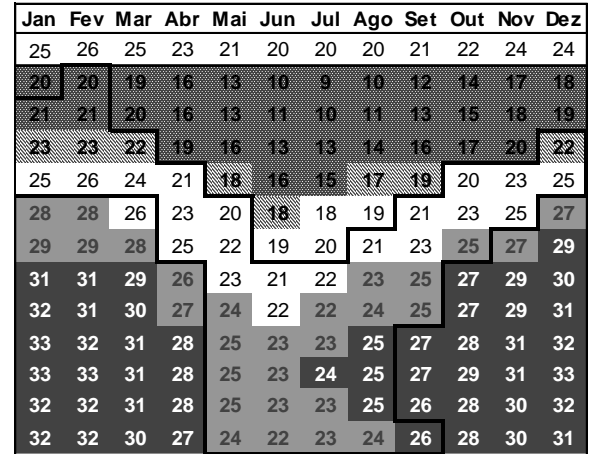

(b) Humphreys (1978)

Jan Fev Mar Abr Mai Jun Jul Ago Set Out Nov Dez \begin{tabular}{|llllllllllll|}
26 & 26 & 25 & 24 & 23 & 22 & 22 & 23 & 23 & 24 & 25 & 25 \\
\hline
\end{tabular} \begin{tabular}{|l|l|llllllllll|}
\hline 20 & 20 & 19 & 16 & 13 & 10 & 9 & 10 & 12 & 14 & 17 & 18 \\
\hline 21 & 21 & 20 & 16 & 13 & 11 & 10 & 11 & 13 & 15 & 18 & 19 \\
\hline
\end{tabular}

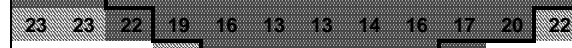
\begin{tabular}{lllllllllllll}
25 & 26 & 24 & 21 & 18 & 16 & 15 & 17 & 19 & 20 & 23 & 25 \\
\hline
\end{tabular} \begin{tabular}{|lll|lllll|lllll|}
\hline 28 & 28 & 26 & 23 & 20 & 18 & 18 & 19 & 21 & 23 & 25 & 27 \\
\hline
\end{tabular} $\begin{array}{llllllllllllll}29 & 29 & 28 & 25 & 22 & 19 & 20 & 21 & 23 & 25 & 27 & 29\end{array}$ $\begin{array}{lllllllllllll}31 & 31 & 29 & 26 & 23 & 21 & 22 & 23 & 25 & 27 & 29 & 30\end{array}$ $\begin{array}{lllllllllllll}32 & 31 & 30 & 27 & 24 & 22 & 22 & 24 & 25 & 27 & 29 & 31\end{array}$ $\begin{array}{lllllllllllll}33 & 32 & 31 & 28 & 25 & 23 & 23 & 25 & 27 & 28 & 31 & 32\end{array}$ $\begin{array}{lllllllllllll}33 & 33 & 31 & 28 & 25 & 23 & 24 & 25 & 27 & 29 & 31 & 33\end{array}$ \begin{tabular}{llll|lllllllll}
32 & 32 & 31 & 28 & 25 & 23 & 23 & 25 & 26 & 28 & 30 & 32
\end{tabular} $\begin{array}{lllllllllllll}32 & 32 & 30 & 27 & 24 & 22 & 23 & 24 & 26 & 28 & 30 & 31\end{array}$ (d) De Dear e Brager (2002)

Zonas de desconforto térmico: Frio Pouco Frio Conforto Pouco calor Calor por Xavier (1999) Figura 8 - Classificação das temperaturas horárias da cidade de Foz do Iguaçu (PR) de acordo com os quatro índices adaptativos

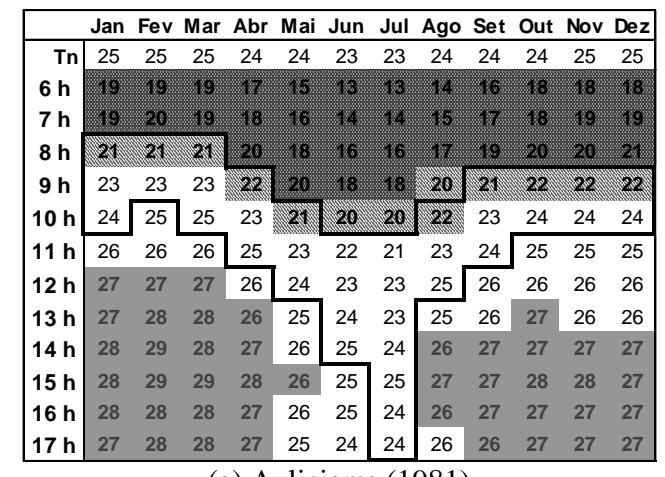

(a) Auliciems (1981)

\begin{tabular}{|c|c|c|c|c|c|c|c|c|c|c|c|c|}
\hline & & & & & & & & & & & & \\
\hline$T n$ & 26 & 26 & 26 & 25 & 24 & 23 & 23 & 24 & 25 & 25 & 25 & 25 \\
\hline & 19 & 19 & 15 & 17 & 15 & 73 & 13 & 14 & 16 & 18 & 18 & 16 \\
\hline & 19 & 20 & 11 & 1) & & & & & & & & 19 \\
\hline $8 \mathrm{n}$ & 21 & 21 & 21 & 20 & & 16 & & 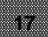 & 19 & 20 & 20 & 21 \\
\hline 91 & 23 & 28 & 23 & 22 & 20 & 18 & 18 & 20 & 21 & 22 & 22 & 22 \\
\hline & 24 & 25 & 25 & 2 & 21 & 20 & 20 & 22 & 23 & 24 & 24 & 24 \\
\hline & 26 & 26 & 26 & 25 & & 22 & & 23 & 24 & 25 & 25 & 25 \\
\hline & 27 & 27 & 27 & 26 & 24 & 23 & 23 & 25 & 26 & 26 & 26 & 26 \\
\hline & 27 & 28 & 28 & 26 & 25 & 24 & 23 & 25 & 26 & 27 & 26 & 26 \\
\hline & 28 & 29 & 28 & 27 & 26 & 25 & 24 & 26 & 27 & 27 & 27 & 27 \\
\hline & 28 & 29 & 29 & 28 & 26 & 25 & 25 & 27 & 27 & 28 & 28 & 27 \\
\hline & 28 & 2 & & & 26 & 25 & 2 & & & & & 27 \\
\hline & & 28 & 28 & 27 & 25 & 24 & & 26 & & & & \\
\hline
\end{tabular}

(c) Nicol e Humphreys (2002)

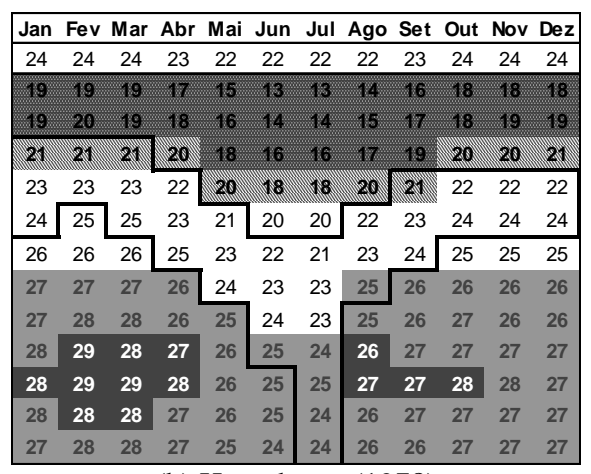

(b) Humphreys (1978)

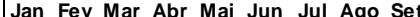
\begin{tabular}{|llllllllllll|}
\hline 25 & 25 & 25 & 24 & 24 & 24 & 23 & 24 & 24 & 25 & 25 & 25 \\
\hline
\end{tabular}

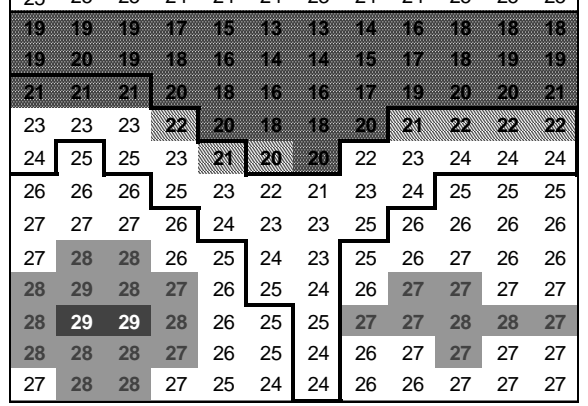

(d) De Dear e Brager (2002)

Zonas de desconforto térmico: Frio mouco Frio Ponforto Pouco calor Calor por Gonçalves (2001)

Figura 9 - Classificação das temperaturas horárias da cidade de Belo Horizonte (MG) de acordo com os quatro índices adaptativos. Em negrito está a zona de conforto definida por Gonçalves (2000) 


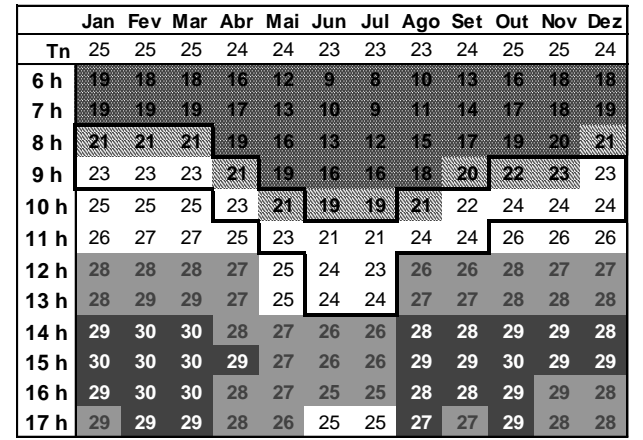

(a) Auliciems (1981)

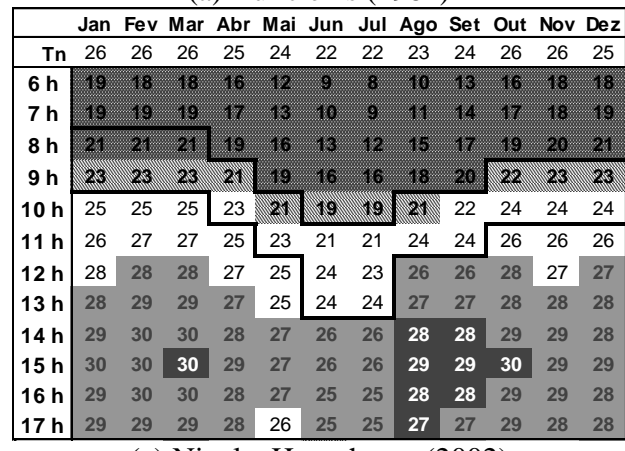

(c) Nicol e Humphreys (2002)

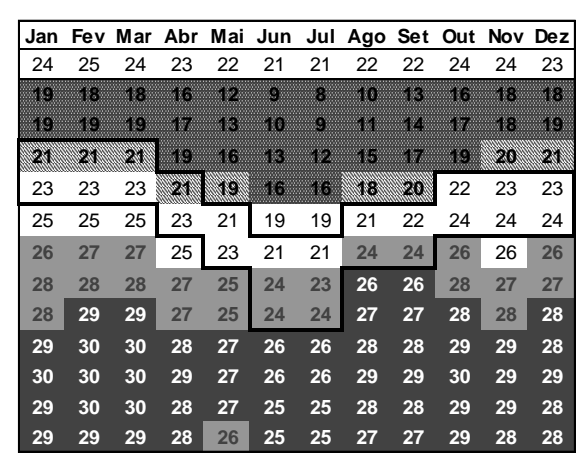

(b) Humphreys (1978)

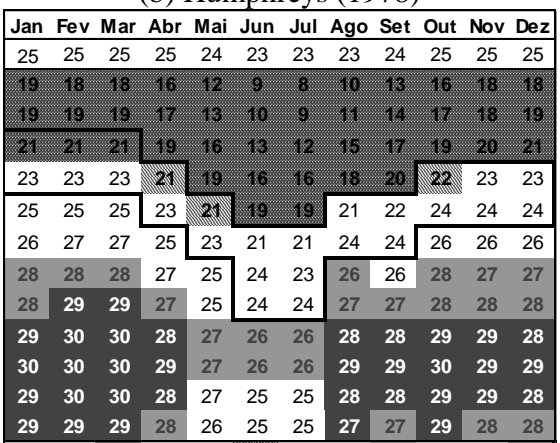

(d) De Dear e Brager (2002)

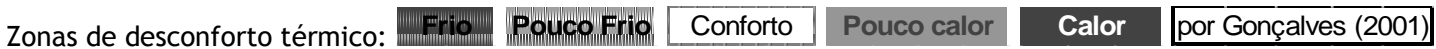

Figura 10 - Classificação das temperaturas horárias da cidade de Bambuí (MG) de acordo com os quatro índices adaptativos. Em negrito está a zona de conforto definida por Gonçalves (2000)

Para Belo Horizonte, o modelo de Auliciems (1981) produziu uma classificação mais próxima da faixa definida por Gonçalves (2000) e, no caso de Bambuí, ambos os modelos de Auliciems (1981) e DeDear e Brager (2002) têm classificações de zonas térmicas mais próximas à faixa definida por Gonçalves (2000). Na classificação obtida pelo modelo de Humphreys (1978), em ambas as cidades, há maior faixa de sensação térmica de desconforto por calor.

Assim, mesmo que o modelo de Humphreys (1978), em algumas cidades, apresente zonas de conforto aproximadas às zonas de conforto pesquisadas pelos autores brasileiros considerados, essa aproximação se reduz quando o modelo é aplicado em cidades de maior amplitude térmica diária. O modelo de Nicols e Humphreys produz, na maioria das cidades, maior período de desconforto por frio e menor por calor. Observa-se que o modelo de Auliciems (1981) produz resultados mais semelhantes em todos os casos, inclusive quando se lida com localidades que possuem amplitudes térmicas maiores, o que caracteriza climas tropicais mais secos ou subtropicais no território nacional.

Para avaliar se essa melhor aproximação do modelo de Auliciems (1981) também pode ser observada quando se utilizam os índices adaptativos como ferramenta de projeto, no item seguinte é apresentado um estudo de caso no qual os quatro modelos são utilizados no dimensionamento de dispositivos de proteção solar para uma sala de uma edificação comercial, com abertura orientada para norte.

\section{Estudo de caso}

Para o dimensionamento de dispositivos de proteção solar, além da trajetória solar, a sensação térmica é importante para a definição dos horários em que é desejável a incidência solar, para aquecimento, ou indesejável, nos dias quentes, para se evitar o sobreaquecimento da edificação. Por isso, neste item, os índices adaptativos são utilizados para determinar quando é necessária a proteção solar em função da sensação térmica da temperatura do ar externo.

\section{Dimensionamento dos brises-soleil}

A definição dos ângulos de proteção solar, para as três cidades, segue os critérios propostos por Pereira e Souza (2008). Os períodos do ano nos quais a incidência da radiação solar é considerada desejável ou não foram determinados em função da temperatura neutra, de acordo com os seguintes critérios:

(a) proteção solar: por se tratar de sala comercial, com carga térmica devida à ocupação mais elevada, a proteção solar deve ser feita quando há 
leve desconforto térmico por calor, ou seja, nos períodos do ano em que a temperatura do ar for superior à temperatura neutra em $2{ }^{\circ} \mathrm{C}$; e

(b) incidência solar desejável: devido à grande área envidraçada, as perdas térmicas podem ser excessivas quando a temperatura do ar estiver baixa. Para compensar as perdas, a incidência solar é considerada desejável se há desconforto térmico por frio, ou seja, quando a temperatura do ar for inferior à temperatura neutra menos $4{ }^{\circ} \mathrm{C}$.

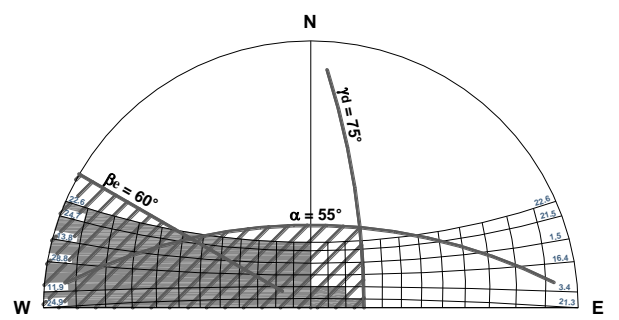

(a) Auliciems (dispositivo misto)

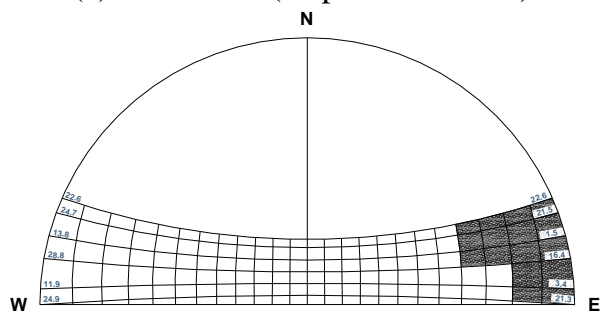

(c) Nicol e Humphreys

Legenda: $\square$ Proteção solar necessária $\square$ Proteção solar indesejável

Figura 11 - Carta solar para uma fachada norte em Fortaleza, com períodos de proteção solar destacados de acordo com os quatro índices

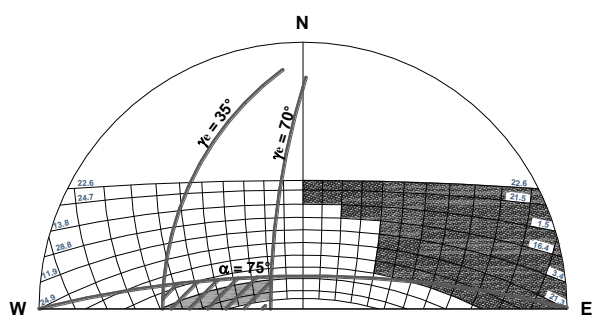

(a) Auliciems (dispositivo horizontal)

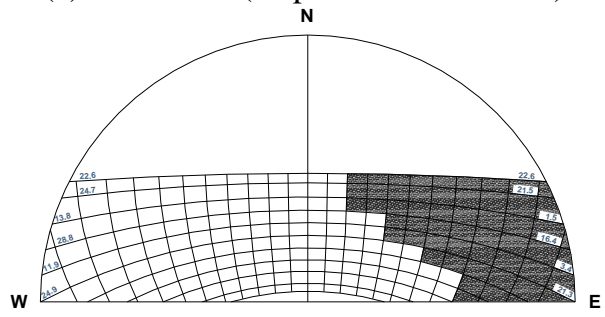

(c) Nicol e Humphreys

\section{Dispositivos de proteção solar obtidos pelos quatro índices}

As cartas solares, com as manchas de desejabilidade/indesejabilidade obtidas pelos quatro índices adaptativos, de acordo com os critérios descritos, são mostradas nas Figuras 11 a 13, para as cidades de Fortaleza, Florianópolis e Belo Horizonte respectivamente. Nessas cartas solares, são propostos ângulos de obstrução para a proteção horizontal $(\alpha)$, vertical $(\beta)$ e limite lateral $(\gamma)$ dos dispositivos sombreadores (brises-soleil). Os índices "e" e "d" indicados referem-se ao lado em que a placa deve ser colocada, à esquerda ou à direita. As Figuras 14 a 16 mostram esses ângulos em projeto.

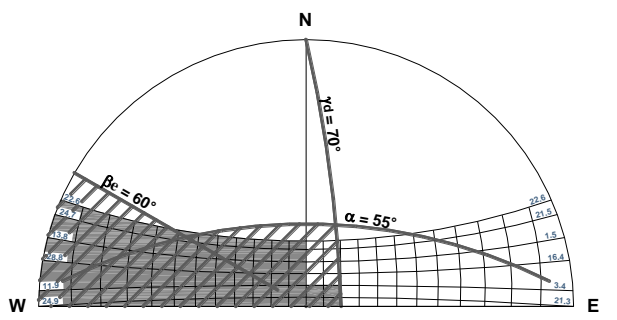

(b) Humphreys (dispositivo misto)

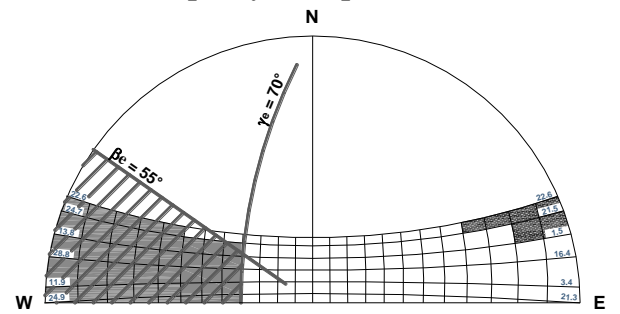

(d) DeDear e Brager (dispositivo vertical)

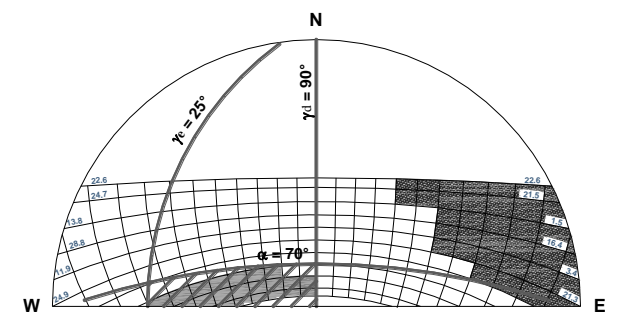

(b) Humphreys (dispositivo horizontal)

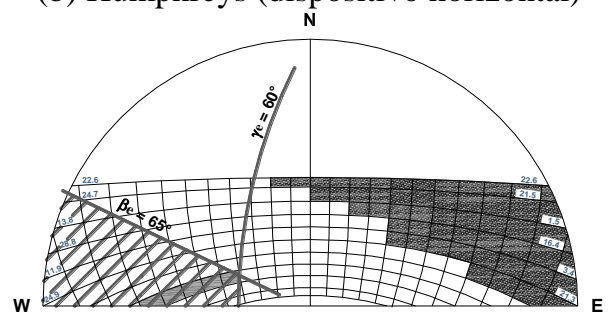

(d) DeDear e Brager (dispositivo vertical)

Legenda: $\square$ Proteção solar necessária $\square$ Proteção solar indesejável 2 Área de proteção solar total do dispositivo Figura 12 - Carta solar para uma fachada norte em Florianópolis, com períodos de proteção solar destacados de acordo com os quatro índices 


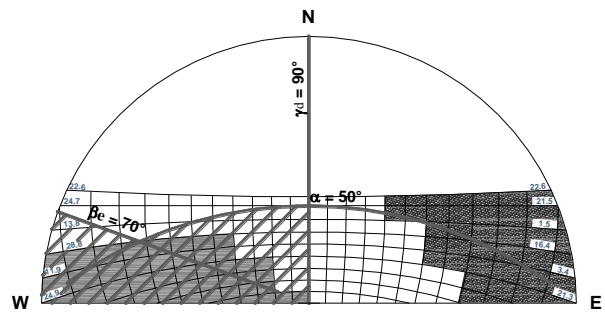

(a) Auliciems (dispositivo misto)

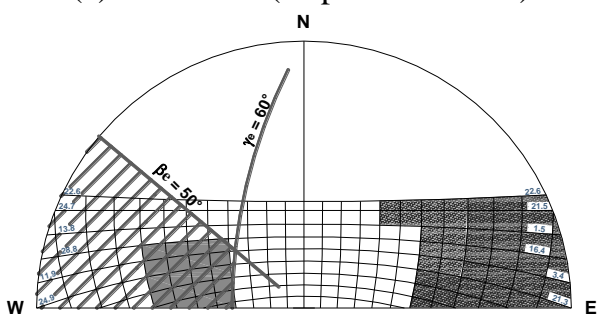

(c) Nicol e Humphreys (dispositivo vertical)

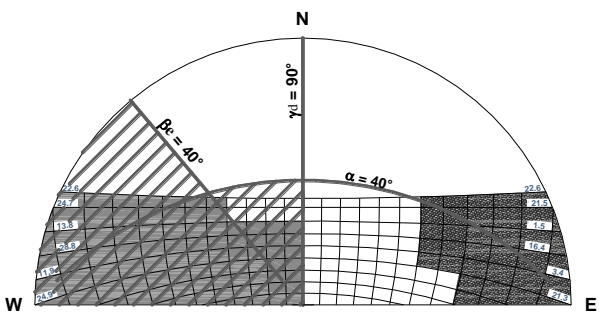

(b) Humphreys (dispositivo misto)

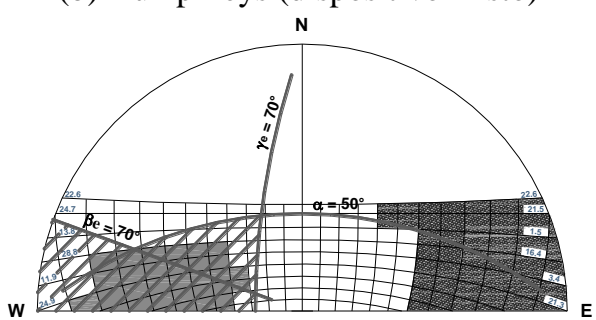

(d) DeDear e Brager (dispositivo misto) Legenda: $\square$ Proteção solar necessária $\square$ Proteção solar indesejável 2 Área de proteção solar total do dispositivo Figura 13 - Carta solar para uma fachada norte em Belo Horizonte, com períodos de proteção solar destacados de acordo com os quatro índices

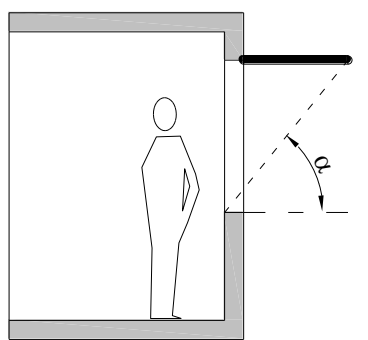

(a) Vista Lateral

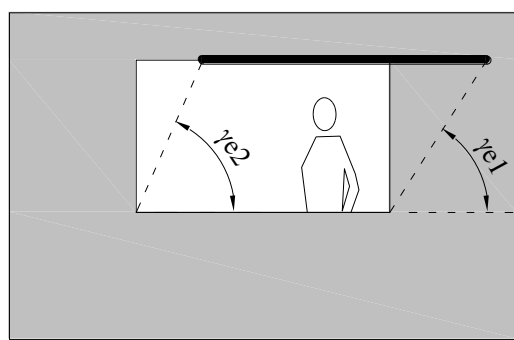

(b) Vista Frontal

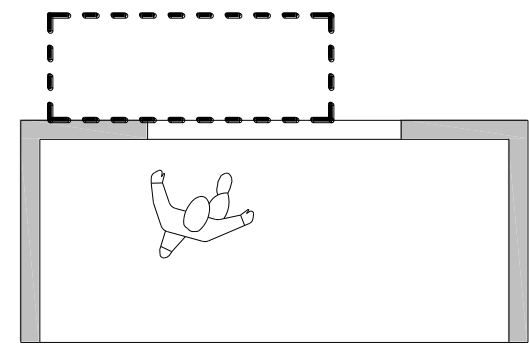

(c) Vista Superior

Figura 14 - Esquema da distribuição dos ângulos de proteção solar em um dispositivo horizontal

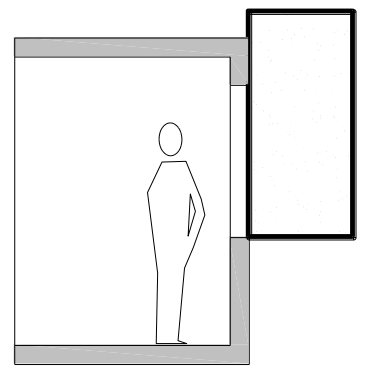

(a) Vista Lateral

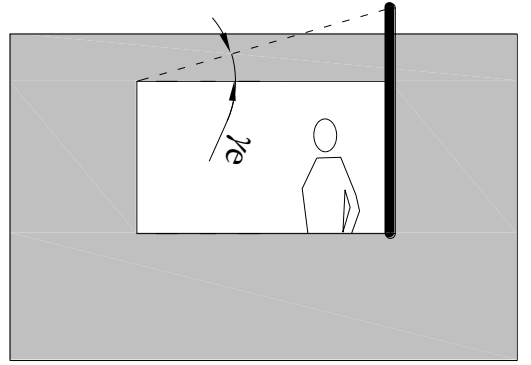

(b) Vista Frontal

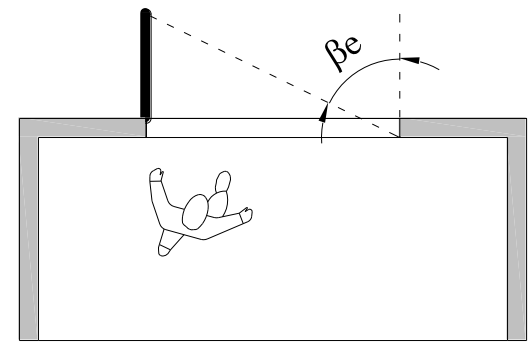

(c) Vista Superior

Figura 15 - Esquema da distribuição dos ângulos de proteção solar em um dispositivo vertical

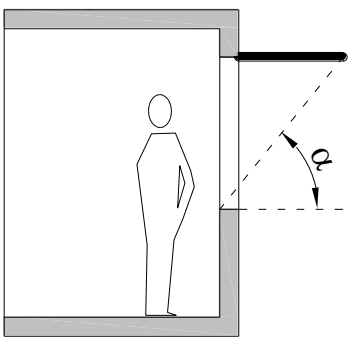

(a) Vista Lateral

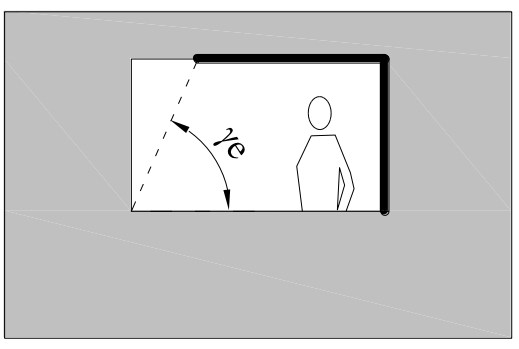

(b) Vista Frontal

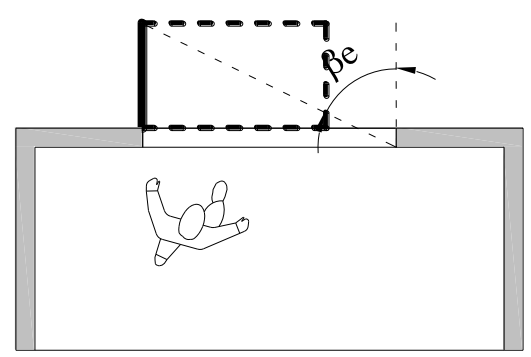

(c) Vista Superior

Figura 16 - Esquema da distribuição dos ângulos de proteção solar em um dispositivo misto 
Por produzir temperaturas neutras mais baixas, o índice de Humphreys (1978) gerou maiores manchas de desconforto por calor (proteção necessária), resultando em dispositivos com maiores ângulos de proteção solar. Já o índice de Nicol e Humphreys (2002), pelo motivo contrário, determinou o dimensionamento de dispositivos com menores ângulos de obstrução celeste ou indicou que não há necessidade de proteção solar na fachada norte, do caso em estudo, para as cidades de Florianópolis e Fortaleza. Nesse caso, optou-se por adotar dispositivos verticais para não obstruir a abóbada celeste próximo ao zênite. Devido à zona de desconforto menos restritiva do índice de DeDear e Brager (2002), os dispositivos encontrados são geometricamente mais simples do que os gerados pela utilização do índice de Auliciems.

Para exemplificar os formatos de brise-soleil gerados em cada caso, são mostrados nas Figuras 14 a 16 esquemas da distribuição dos ângulos de proteção solar num dispositivo horizontal, vertical e misto respectivamente.

\section{Casos simulados}

Visto que os resultados produzidos por diferentes autores são, por vezes, parecidos ou idênticos, os ângulos de proteção solar são agrupados em casos de estudo por similaridade de formatos. O Quadro 4 mostra o agrupamento, listando, por cidade, os ângulos de proteção e o índice que gerou o formato, por caso simulado. Como em Fortaleza e Florianópolis o modelo de Nicol e Humphreys (2002) não indicou a necessidade de sombreamento, essas cidades têm apenas dois casos simulados, além do caso de referência.

\section{Ambiente estudado e parâmetros de simulação adotados}

Tomou-se como caso uma sala comercial, localizada num pavimento intermediário, com fachada externa voltada para o norte. Uma síntese das demais características simuladas é apresentada: (a) dimensões: sala - 7,0 $\mathrm{m} \times 5,0 \mathrm{~m} \times 2,8 \mathrm{~m}$; janela $-5,0 \mathrm{~m}$ x 1,5 m;

(b) ocupação: 5 pessoas, lâmpadas, computadores, horário comercial, todo o ano;

(c) renovação do ar: ventilação natural permanente, com taxa média de 10 renovações por hora;

(d) materiais: paredes de tijolo furado rebocadas e pintadas (Coeficiente global de transmissão térmica $\mathrm{U}=2,85 \mathrm{~W} / \mathrm{m}^{2} \mathrm{~K}$, fator de calor solar $\mathrm{FCS}=$ $3,42)$, e teto de laje de concreto $\left(\mathrm{U}=3,31 \mathrm{~W} / \mathrm{m}^{2} \mathrm{~K}\right.$ para fluxo ascendente, e $\mathrm{U}=2,26 \mathrm{~W} / \mathrm{m}^{2} \mathrm{~K}$ para fluxo descendente);

(e) software utilizado: EnergyPlus, versão 2.2.0; e

(f) tipo de simulação: anual (8.760 horas). Arquivos climáticos: tipo SWERA ${ }^{4}$.

\section{Resultados da Simulação}

\section{Ganho térmico solar pelas janelas}

O primeiro resultado analisado é a efetividade dos dispositivos em barrar a incidência solar sobre a janela nos períodos de insolação indesejável. As Figuras 17, 19 e 21 mostram esse resultado, através de gráficos da radiação solar horária incidente sobre a superfície da janela, no $15^{\circ}$ dia de cada mês do ano, para as cidades de Fortaleza, Belo Horizonte e Florianópolis respectivamente. Outra análise importante é a resultante redução na carga térmica solar total dentro do ambiente. As Figuras 18, 20 e 22 apresentam o ganho térmico solar proveniente da janela.

\footnotetext{
${ }^{4}$ Os dados dos arquivos climáticos TMY utilizados referem-se ao projeto do Solar and Wind Energy Resource Assessment (SWERA). Disponível em: <http://apps1.eere.energy.gov/buildings/ energyplus/cfm/weather_data.cfm>.
} 


\begin{tabular}{|l|c|c|c|}
\hline Casos Simulados & Fortaleza & Florianópolis & Belo Horizonte \\
\hline Caso de Referência & Sem proteção solar & Sem proteção solar & Sem proteção solar \\
\hline $\begin{array}{l}\text { Caso 1: } \text { misto ou } \\
\text { horizontal }\end{array}$ & $\alpha=55^{\circ}, \beta_{\mathrm{e}}=70^{\circ}, \gamma_{\mathrm{d}}=70$ & $\alpha=70^{\circ}, \gamma_{\mathrm{e}}=25^{\circ}$ e $\gamma_{\mathrm{d}}=90^{\circ}$ & $\alpha=55^{\circ}, \beta_{\mathrm{e}}=70^{\circ}, \gamma_{\mathrm{d}}=90$ \\
\hline Caso 2: vertical & $\beta_{\mathrm{e}}=55^{\circ}, \gamma_{\mathrm{e}}=70^{\circ}$ & $\beta_{\mathrm{e}}=65^{\circ}, \gamma_{\mathrm{e}}=60^{\circ}$ & $\beta_{\mathrm{e}}=50^{\circ}, \gamma_{\mathrm{e}}=60^{\circ}$ \\
\hline $\begin{array}{l}\text { Caso 3: } \text { misto com } \\
\text { maior obstrução }\end{array}$ & deDear e Brager & & Nicol e Humphreys \\
\hline
\end{tabular}

Quadro 4 - Resumo dos tipos de dispositivos simulados por cidade

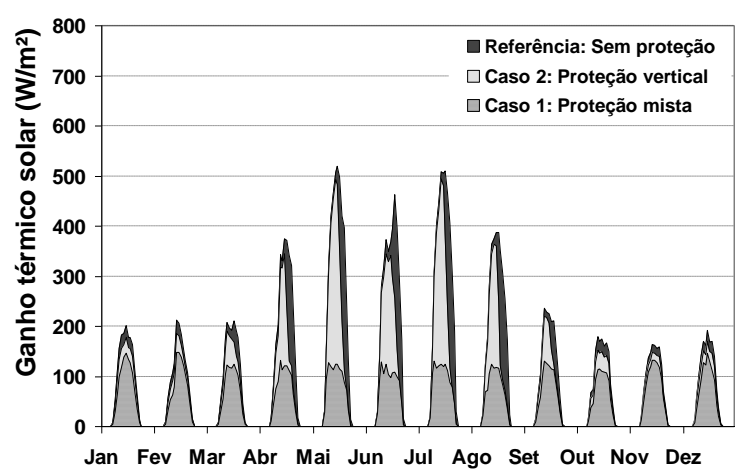

Figura 17 - Ganho térmico solar horário pela janela, norte, Fortaleza, no $15^{\circ}$ dia do mês

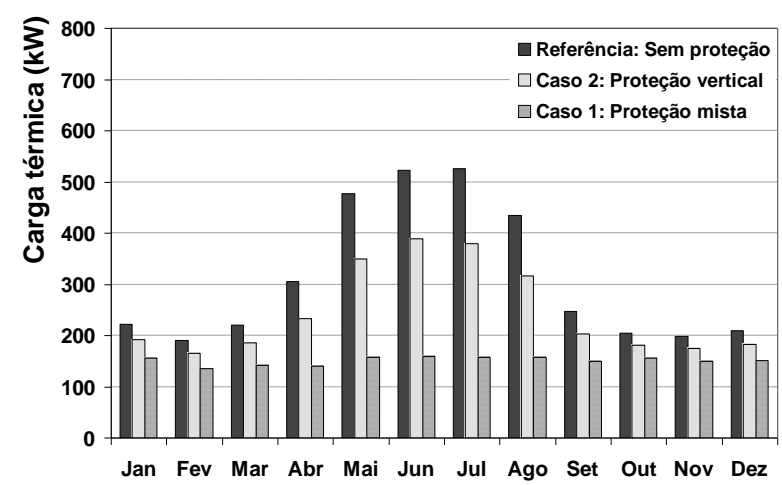

Figura 18 - Carga térmica solar mensal total (apenas pela janela) para Fortaleza

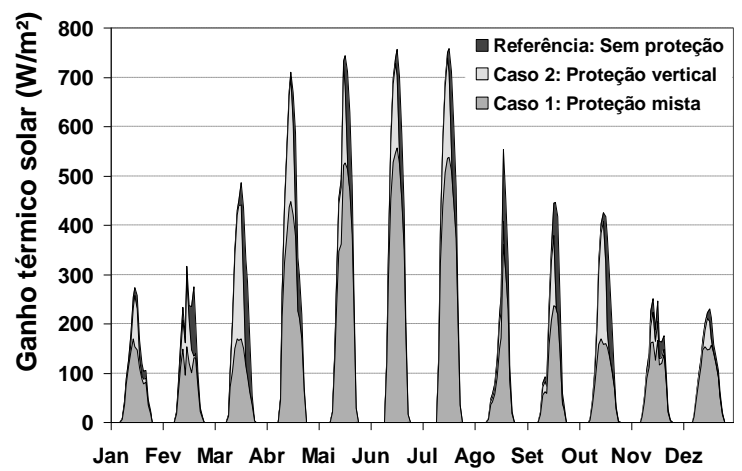

Figura 19 - Ganho térmico solar horário pela janela, norte, Florianópolis, no $15^{\circ}$ dia do mês 


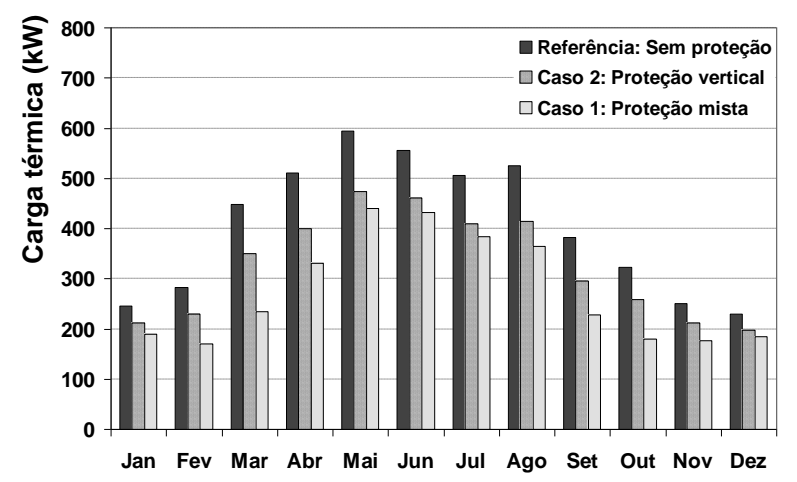

Figura 20 - Carga térmica solar mensal total (apenas pela janela) para Florianópolis

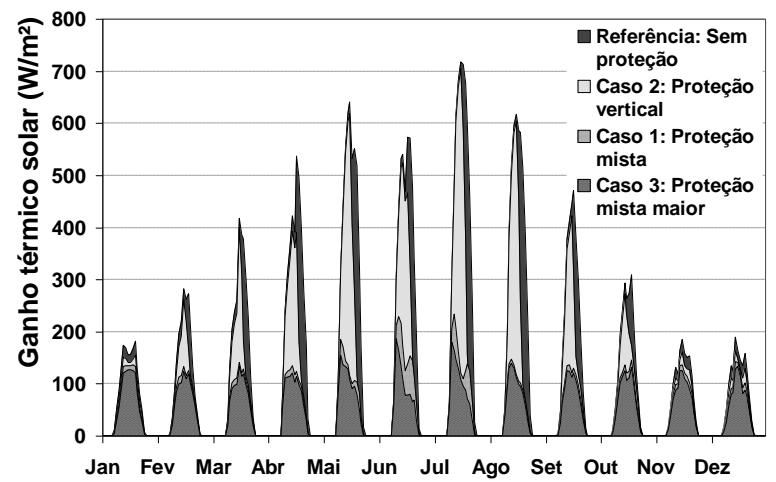

Figura 21 - Ganho térmico solar sobre a janela, norte, no $15^{\circ}$ dia do mês para Belo Horizonte

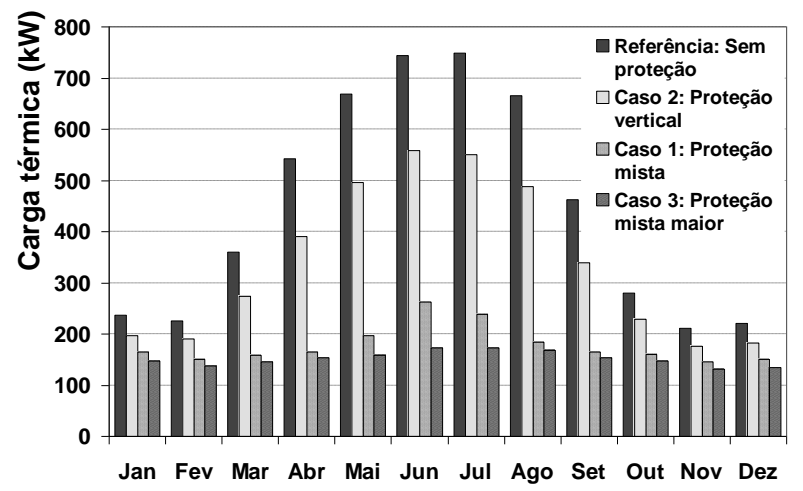

Figura 22 - Carga térmica solar mensal total (apenas pela janela) para Belo Horizonte

\section{Carga térmica solar em Fortaleza}

Pelo gráfico de ganho térmico, observa-se que os dois dispositivos projetados funcionam atendendo aos objetivos para os quais são projetados. O dispositivo de proteção solar vertical somente reduziu a carga térmica durante o período da tarde, e o dispositivo misto ofereceu proteção no período de pico da incidência (meio-dia) e à tarde.

\section{Carga térmica solar em Florianópolis}

Com a proteção horizontal, a redução no ganho térmico solar ocorre próximo ao meio-dia, horário de pico de incidência. Já a proteção vertical causou redução no ganho térmico no período da tarde. A carga térmica mensal teve redução de $32 \%$ no caso 1 com relação ao caso de referência e de $19 \%$ no caso 2.

\section{Carga térmica solar em Belo Horizonte}

O dispositivo vertical oferece proteção no período da tarde. Os dispositivos mistos protegem da incidência solar próximo ao meio-dia e à tarde, sendo que o maior dispositivo oferece maior proteção. A redução na carga térmica total ocorrida, com relação ao caso de referência, é $60 \%, 24 \%$ e $66 \%$ para os casos 1,2 e 3 respectivamente. 


\section{Horas de conforto}

Essa análise foi feita pela comparação da temperatura do ar horária, interna e externa, com a faixa definida para cada cidade pelos autores brasileiros, e apresentada no Quadro 2. A Tabela 3 apresenta uma síntese dos resultados obtidos em termos de percentual de horas com temperatura do ar dentro da faixa, acima e abaixo, no período de ocupação, entre $8 \mathrm{~h}$ e $18 \mathrm{~h}$.

Em comparação com o exterior, o caso de referência possui menor número de horas na faixa definida. Isso se deve ao fato de que a sala comercial simulada possui elevada carga térmica, o que causa aumento do desconforto por calor. Belo Horizonte foi o local onde o uso de proteção gerou maior benefício. $\mathrm{O}$ uso de dispositivos mistos aumentou cerca de $6 \%$ o número de horas na faixa e reduziu em $8 \%$ o número de horas acima dela.

Nos demais casos, de modo geral, observou-se que o uso de dispositivos de proteção solar oferece pequena melhora no desempenho térmico do ambiente, quando comparados ao caso de referência. Esse benefício ocorre principalmente devido à redução na temperatura máxima interna, como mostrado pelos gráficos das Figuras 23 a 25 , para as cidades de Fortaleza, Belo Horizonte e Florianópolis, numa semana do mês de maio, período crítico para a incidência de radiação solar e sem chuvas nas três cidades.

\begin{tabular}{|c|c|c|c|c|c|c|c|c|}
\hline \multirow{2}{*}{$\begin{array}{r}\begin{array}{r}\text { Parâmetros de } \\
\text { conforto adotados }\end{array} \\
\text { Sensação } \\
\end{array}$} & \multicolumn{2}{|c|}{$\begin{array}{c}\text { Fortaleza } \\
(\text { Araújo, 1996) }\end{array}$} & \multicolumn{3}{|c|}{$\begin{array}{c}\text { Florianópolis } \\
\text { (Xavier, 1999) } \\
\end{array}$} & \multicolumn{3}{|c|}{$\begin{array}{c}\text { Belo Horizonte } \\
\text { (Gonçalves, 2000) }\end{array}$} \\
\hline & $\Leftrightarrow$ & 仓 & $\Leftrightarrow$ & 仓 & $\sqrt{n}$ & $\Leftrightarrow$ & 仓 & $\sqrt{n}$ \\
\hline Exterior & $19,1 \%$ & $60,8 \%$ & $42,7 \%$ & $19,3 \%$ & $21,3 \%$ & $36,3 \%$ & $47,9 \%$ & $15,8 \%$ \\
\hline Caso de Referência & $9,0 \%$ & $74,3 \%$ & $42,2 \%$ & $27,9 \%$ & $13,2 \%$ & $32,4 \%$ & $61,9 \%$ & $5,7 \%$ \\
\hline Caso 1 & $11,2 \%$ & $72,1 \%$ & $43,2 \%$ & $25,8 \%$ & $14,4 \%$ & $38,5 \%$ & $53,2 \%$ & $8,2 \%$ \\
\hline Caso 2 & $9,6 \%$ & $73,8 \%$ & $42,7 \%$ & $27,0 \%$ & $13,6 \%$ & $34,7 \%$ & $59,2 \%$ & $6,1 \%$ \\
\hline Caso 3 & \multicolumn{2}{|c|}{-} & \multicolumn{3}{|c|}{-} & $38,8 \%$ & $52,5 \%$ & $8,7 \%$ \\
\hline
\end{tabular}

Legenda: $\Leftrightarrow$ Temperatura do ar dentro da faixa definida pelos autores; 仓 Tar acima da faixa.; 凤 Tar abaixo da faixa

Tabela 3 - Frequência de horas com temperaturas dentro da faixa definida

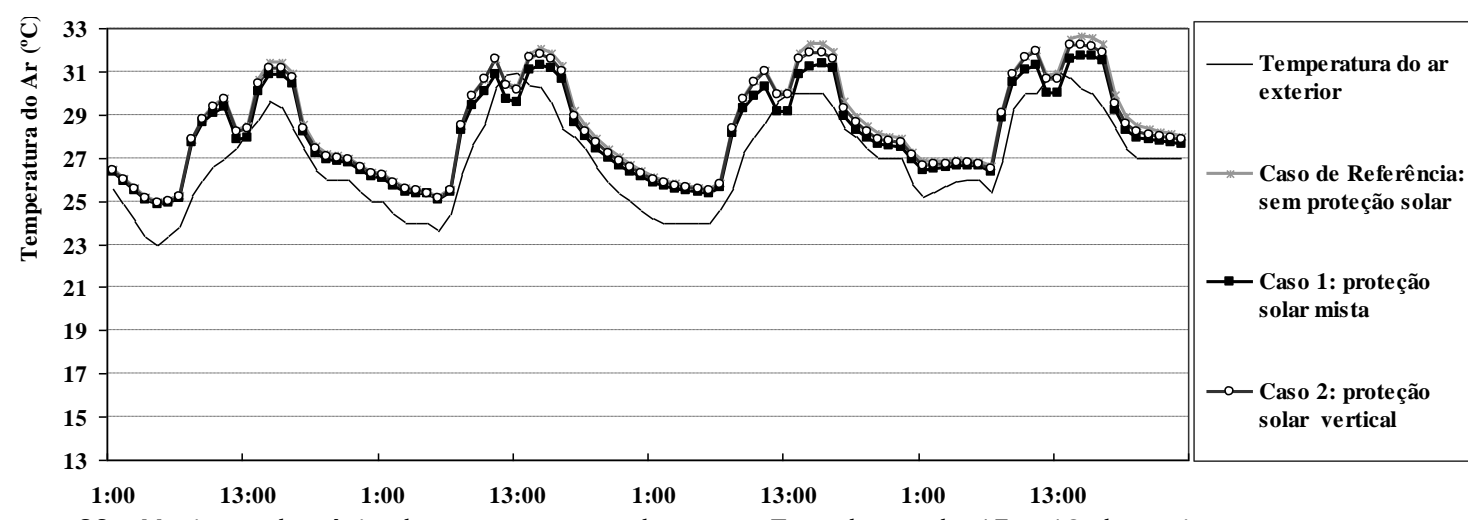

Figura 23 - Variação horária da temperatura do ar em Fortaleza, de 15 a 18 de maio

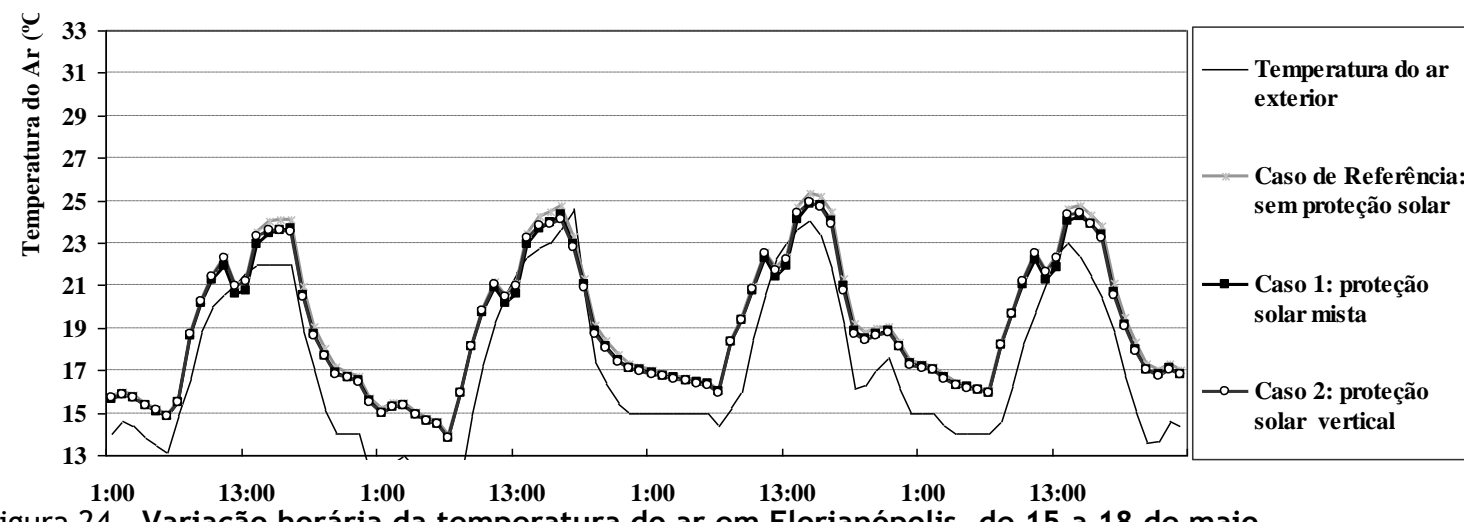

Figura 24 - Variação horária da temperatura do ar em Florianópolis, de 15 a 18 de maio 


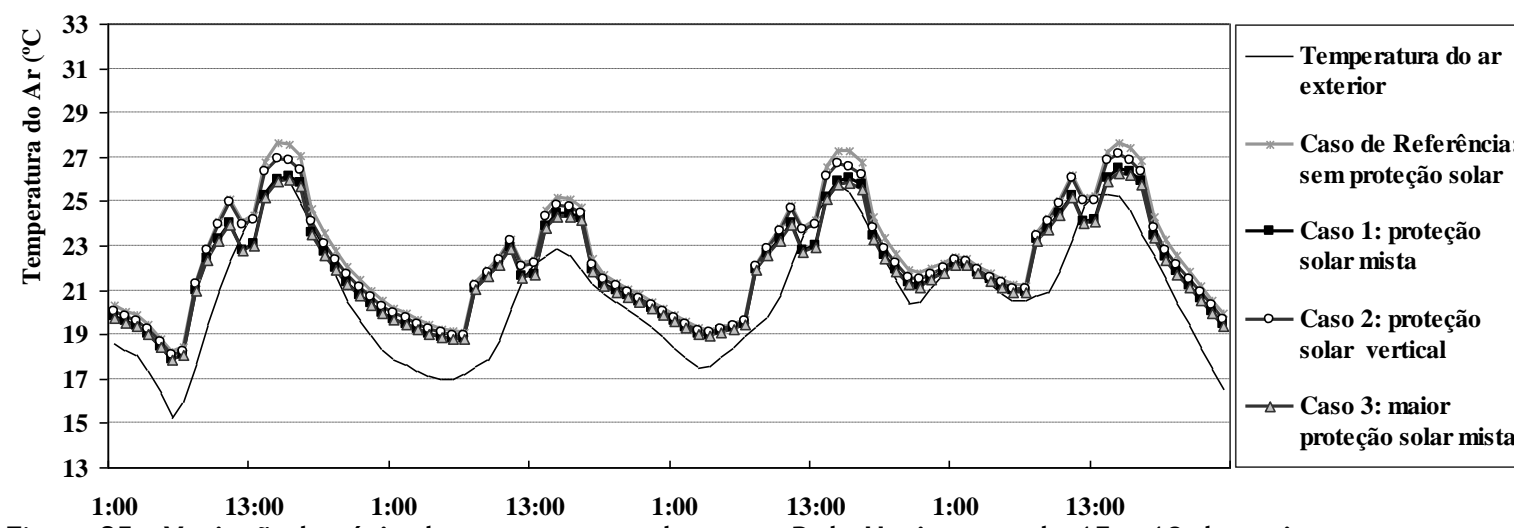

Figura 25 - Variação horária da temperatura do ar em Belo Horizonte, de 15 a 18 de maio

Através desses gráficos, observa-se que a influência do uso de dispositivos de proteção solar sobre a variação da temperatura do ar é da ordem de décimos, em ambientes com permanente renovação do ar.

Apesar da pouca interferência do uso de dispositivos de proteção solar na temperatura do ar, o uso de dispositivos adequadamente dimensionados possui impacto no conforto térmico. A análise dessa influência pode ser feita a partir do estudo de outras variáveis, que se relacionam com quantidade de radiação existente no ambiente, como a temperatura radiante ou a temperatura operativa, o que é discutido no capítulo a seguir.

\section{Variação diária da temperatura radiante}

A temperatura do ar é determinante para as trocas térmicas convectivas entre a pele e o ar, cerca de $40 \%$ das trocas entre o ser homem e o meio. Contudo, o balanço térmico de indivíduos também envolve trocas radiativas, responsáveis por outros $40 \%$ das trocas térmicas. A variável determinante desse processo é a temperatura radiante média.

Visto que dispositivos de proteção solar atuam diretamente na redução da carga térmica por radiação, a temperatura radiante média da sala deve ser um indicador melhor do impacto da utilização desses dispositivos sobre o conforto térmico no ambiente.

As Figuras 26, 27 e 28 mostram a variação horária da temperatura radiante média nos casos simulados para Fortaleza, Florianópolis e Belo Horizonte, do dia 15 ao dia 18 de maio.

Em Fortaleza, o uso de uma placa vertical reduziu em até $1{ }^{\circ} \mathrm{C}$ a temperatura radiante, e o uso de placa mista reduziu em até $2{ }^{\circ} \mathrm{C}$, quando comparado com a temperatura radiante da sala sem nenhum dispositivo de proteção. Como Araújo (1996) apresenta parâmetros de conforto térmico para a variável temperatura radiante, é possível avaliar o benefício do uso de dispositivo de proteção solar para a melhoria da sensação térmica, na Figura 26, onde se observa que a curva que mais se aproxima desse valor é a do caso 1 . Considerando a temperatura radiante durante o período de ocupação, é possível demonstrar maior contribuição do uso de proteção solar para o conforto térmico. O caso de referência possui $57,1 \%$ de horas dentro da faixa estabelecida por Araújo; o caso 1, 80,5\%; e o caso 2, 65,2\%.

Em Florianópolis, uma redução na temperatura radiante pode impactar o conforto de maneira negativa, reforçando a sensação térmica de frio pelos usuários no período de inverno. Mas como ambos os casos permitem a incidência solar nesse período, essa redução é pequena.

Em Belo Horizonte, o gráfico mostra que o uso de dispositivo de proteção solar misto é o mais efetivo na redução da temperatura radiante, mas as diferenças de redução entre placas com obstrução grande (caso 2) e média (caso 1) são pequenas.

\section{Variação da temperatura operativa}

Além da temperatura radiante, a temperatura operativa pode ser utilizada como indicador do impacto do uso de proteção solar no desempenho térmico do ambiente por relacionar temperatura do ar e temperatura radiante. Considerando essa variável como a média aritmética entre a temperatura radiante e a temperatura do ar, é possível comparar as temperaturas nos casos simulados aos parâmetros de temperatura operativa definidos pelos autores brasileiros. 


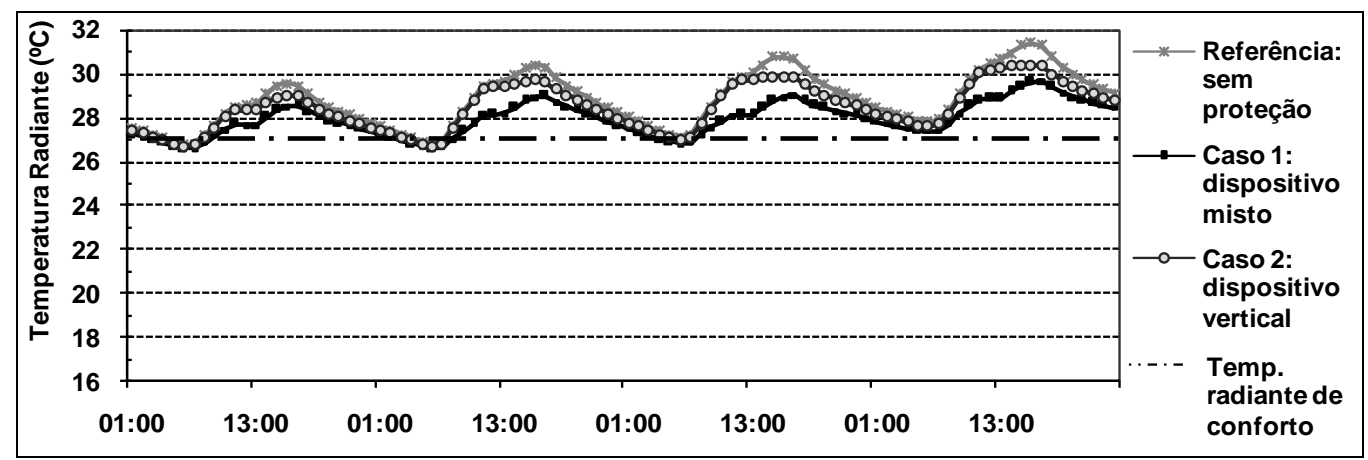

Figura 26 - Variação da temperatura radiante nos dias 15 a 18 de maio em Fortaleza

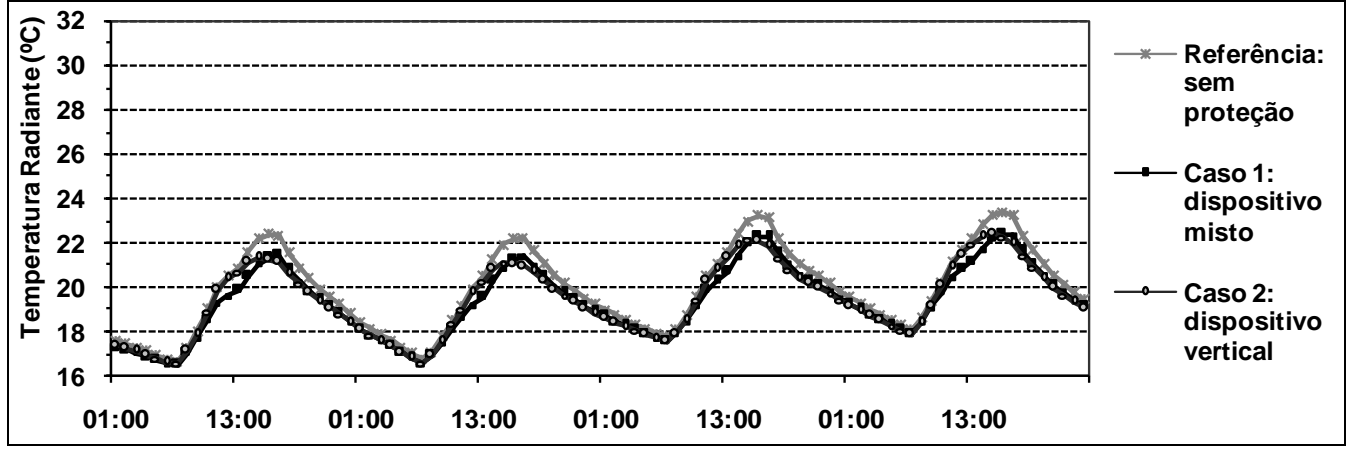

Figura 27 - Variação da temperatura radiante nos dias 15 a 18 de maio em Florianópolis

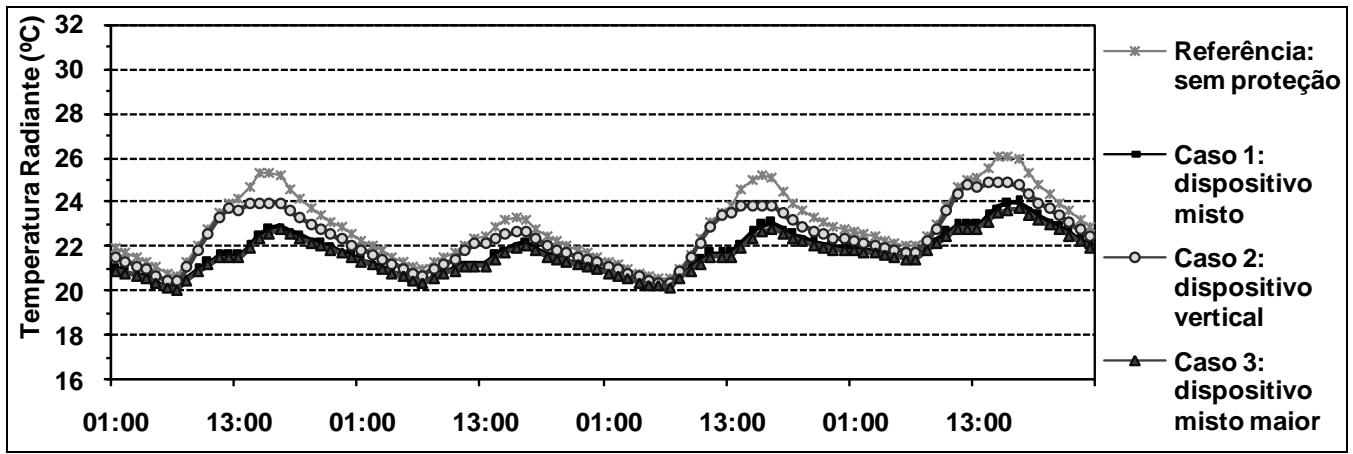

Figura 28 - Variação da temperatura radiante nos dias 15 a 18 de maio em Belo Horizonte

A Tabela 4 apresenta uma síntese dos resultados obtidos em termos de percentual de horas dentro da faixa ótima de temperatura operativa definida pelos autores nacionais, entre $8 \mathrm{~h}$ e $18 \mathrm{~h}$.

Nos três casos, o maior benefício ocorreu no caso 1 de Fortaleza, no qual houve um aumento de $14 \%$ no número de horas dentro da faixa definida por Araújo. Em Florianópolis e Belo Horizonte, o desempenho dos ambientes com relação à temperatura operativa foi semelhante ao da temperatura do ar, mostrado na Tabela 1, sendo a aproximação com relação aos parâmetros definidos pelos autores nacionais um pouco menor com relação à temperatura operativa.

\section{Conclusões}

\section{Limites do trabalho}

Os valores de zona de conforto térmico têm como referência três trabalhos brasileiros, considerando os limites definidos por esses autores como representativos da aclimatação da população local. Tais limites são específicos para as regiões climáticas em que foram desenvolvidos, assim os resultados aqui encontrados não cobrem toda a diversidade de climas existente no país. 


\begin{tabular}{|c|c|c|c|c|c|c|c|c|}
\hline \multirow{2}{*}{\begin{tabular}{|r|}
$\begin{array}{r}\text { Parâmetros de } \\
\text { conforto adotados }\end{array}$ \\
Sensação \\
\end{tabular}} & \multicolumn{2}{|c|}{$\begin{array}{c}\text { Fortaleza } \\
(\text { Araújo, 1996) } \\
\end{array}$} & \multicolumn{3}{|c|}{$\begin{array}{l}\text { Florianópolis } \\
\text { (Xavier, 1999) } \\
\end{array}$} & \multicolumn{3}{|c|}{$\begin{array}{c}\text { Belo Horizonte } \\
\text { (Gonçalves, 2000) }\end{array}$} \\
\hline & $\Leftrightarrow$ & 仓 & $\Leftrightarrow$ & 仓 & $\sqrt{n}$ & $\Leftrightarrow$ & 仓 & $\sqrt{n}$ \\
\hline Caso de Referência & $25,7 \%$ & $74,2 \%$ & $55,3 \%$ & $26,9 \%$ & $17,8 \%$ & $42,2 \%$ & $50,9 \%$ & $6,8 \%$ \\
\hline Caso 1 & $39,7 \%$ & $60,3 \%$ & $55,9 \%$ & $23,2 \%$ & $20,9 \%$ & $46,7 \%$ & $39,0 \%$ & $14,4 \%$ \\
\hline Caso 2 & $29,4 \%$ & $70,5 \%$ & $55,3 \%$ & $25,2 \%$ & $19,5 \%$ & $46,3 \%$ & $45,7 \%$ & $8,1 \%$ \\
\hline Caso 3 & & & & - & & $46,4 \%$ & $38,2 \%$ & $15,5 \%$ \\
\hline
\end{tabular}

Legenda: $\Leftrightarrow$ Temperatura operativa dentro da faixa definida pelos autores; $\uparrow$ Top. acima da faixa.; $\sqrt{ }$ Top. ahaixo da faixa

Tabela 2 - Frequência de horas com temperatura operativa dentro dos parâmetros definidos

Com relação aos índices adaptativos, considera-se que o método de cálculo da temperatura média mensal externa existente nesses índices é o mesmo adotado como padrão mundial pela WMO e, portanto, no cálculo das normais climatológicas brasileiras, visto que não há referência ao método de cálculo da temperatura média adotado pelos autores considerados.

Nos modelos adaptativos, a variação da temperatura de neutralidade depende das possibilidades de adaptação do usuário existentes no período de medição. Como neste artigo esses índices são comparados a valores obtidos em salas de aulas, nas quais as variáveis humanas como idade, nível de atividade e vestimenta são mais controladas, os resultados encontrados são representativos de ambientes com menores possibilidades de adaptação.

As simulações foram realizadas com o objetivo de verificar o uso dos índices como ferramenta projetual, e não para testar o desempenho de uma solução arquitetônica específica. Assim, os resultados encontrados na simulação se aplicam somente ao caso estudado, e podem ser diferentes em outros ambientes.

Na maioria das comparações dos casos simulados, observou-se uma pequena variação da temperatura do ar. Esse resultado provavelmente ocorreu porque é mantida uma renovação natural do ar permanente no ambiente de estudo, o que aproxima a temperatura interna do ar à externa, mascarando o efeito dos brises-soleil.

Como mostrado por Pereira (2004) e por Loura (2006), o modelo de balanço de umidade do ar do software EnergyPlus ${ }^{\circledR}$ possui uma limitação quando simula ambientes com taxas de renovação do ar muito abaixo da considerada higiênica e com umidade do ar elevada. Assim sendo, para que a simulação gere resultados confiáveis, não se deve, por exemplo, trabalhar com o caso do ambiente sem ventilação ou apenas com infiltração do ar (janelas fechadas). Por outro lado, não haveria sentido em considerar o ambiente de estudo climatizado artificialmente, o que teria como efeito manter praticamente constante a temperatura interna do ar. Esta, porém, é utilizada neste estudo como indicador do efeito das proteções solares sobre a sensação térmica de usuários aclimatados, tendo em vista que os índices adaptativos só trabalham com essa variável.

\section{Seleção do índice adaptativo}

Após as várias comparações realizadas neste trabalho, verificou-se que a temperatura neutra resultante das equações propostas por Auliciems (1981) e DeDear e Bragger (2002) apresentam melhor resultado. Com relação à amplitude da zona de conforto térmico, o melhor resultado encontrado são as faixas de $T_{n} \pm 2{ }^{\circ} \mathrm{C}$, para pouco desconforto, e $\mathrm{T}_{\mathrm{n}} \pm 4{ }^{\circ} \mathrm{C}$, para desconforto.

O modelo de Humphreys (1978) mostrou boa aproximação nas localidades de climas sem grandes amplitudes térmicas. Contudo, em cidades de clima mais seco ou subtropical, com maior amplitude térmica diária, o modelo gera temperaturas neutras mais baixas, causando um resultado elevado de desconforto por calor.

Já o modelo proposto por Nicol e Humphreys (2002) não apresentou aproximação com as faixas definidas pelos autores nacionais em nenhuma das cidades avaliadas. Por esse modelo são obtidos maiores períodos de desconforto por frio e poucos horários de desconforto por calor. Esses resultados provavelmente estão relacionados com a amostra populacional tomada para a realização das medições que geraram esses índices.

\section{Utilização dos modelos adaptativos}

Um índice adaptativo ajustado parece ser um bom critério para a definição de soluções projetuais que lidam com estratégias bioclimáticas, podendo ser aplicado para se predizer a condição de conforto quando a única informação disponível é a temperatura do ar externo.

$\mathrm{O}$ índice que demonstrou melhor compatibilidade, de Auliciems (caso 1), quando utilizado no projeto de dispositivo de proteção solar, foi capaz de 
indicar soluções adequadas ao local: proteção solar ao longo do ano para a cidade com constante clima quente; proteção solar parcial para o inverno ameno, mas com elevada carga térmica solar, do tropical semiárido; e pequena proteção solar, sem comprometimento do aquecimento passivo durante o inverno, no clima subtropical.

O uso do modelo de Humphreys (1978) produziu resultados semelhantes ao de Auliciems (1981) nas três cidades e o uso do modelo de DeDear e Brager (2002) gerou resultados menos adequados em Fortaleza e Florianópolis do que o de Auliciems. É válido lembrar que ambos os modelos geram temperatura neutra próxima, mas a faixa de DeDear e Brager (2002) é um pouco menos restritiva. Por fim, o uso do modelo de Nicol e Humphreys (2002) foi o que apresentou o pior resultado em todos os casos avaliados, inclusive indicando que não havia necessidade de uso de proteção solar em locais onde seu uso trouxe melhoria na sensação de conforto térmico ou indicando menor proteção do que aquela que teve melhor desempenho.

Com relação ao uso dos brises-soleil, mesmo que a melhoria no número de horas de conforto seja pequena, ela ocorre no período mais crítico para o conforto térmico: no horário das temperaturas mais elevadas do ano.

Apesar de suas vantagens, os índices adaptativos possuem limitações na determinação das condições de conforto térmico dos usuários de uma edificação. Como mostrado neste trabalho, a variável temperatura do ar, única considerada por eles, não é suficiente para destacar a influência das soluções obtidas no conforto térmico do usuário. Assim, em situações mais complexas, observou-se a necessidade da adoção de outras variáveis. Neste trabalho, a temperatura operativa mostrou melhor adequação às condições de climas tropicais úmidos, nos quais há grande impacto da carga térmica devido à radiação solar.

\section{Referências}

\begin{abstract}
ARAÚJO, V. M. D. Parâmetros de Conforto Térmico para Usuários de Edificações Escolares no Litoral Nordestino Brasileiro. 1996. 179 f.

Tese (Doutorado em Arquitetura e Urbanismo) Faculdade de Arquitetura e Urbanismo da Universidade de São Paulo, São Paulo, 1996.
\end{abstract}

ASHRAE. Standard 55: thermal environment conditions for human occupancy. Atlanta: American Society of Heating, Refrigerating and Air-Conditioning Engineers, 2004.
ASSIS, Eleonora S. Método Integrado de Análise Climática para Arquitetura Aplicado à Cidade de Belo Horizonte, MG. In: Encontro Nacional, 6., e Encontro Latino-Americano Sobre Conforto no Ambiente Construído, 3., 2001, São Pedro. Anais... São Paulo, ANTAC, 2001. 1 CD-ROM.

AULICIEMS, A. Psycho-Physiological Criteria for Global Thermal Zones of Building Design. International Journal of Biometeorology, 1981.

BRAGER, G.; DEDEAR, R. J. Thermal Adaptation in the Built Environment: a literature review. Energy and Building, v. 17, p. 83-96, 1998.

BRASIL. Ministério da Agricultura e Reforma Agrária, Departamento Nacional de Meteorologia. Normais Climatológicas 1961-1990. Brasília: DNMET, 1992.

DEDEAR, R. A Global Database of Thermal Comfort Field Experiments. AHSRAE

Transactions, v. 104, n. 1, p. 1141-1152, 1998.

DEDEAR, R. J.; BRAGER, G. S. Thermal Comfort in Naturally Ventilated Buildings: revisions to ASHRAE Standard 55. Energy and Buildings, v. 34, n. 6, p. 549-561, jul. 2002.

ECHENIQUE, M. Modelos: una discussion. In: MARTIN, L.; MARCH, L.; ECHENIQUE, M. La Estructura del Espacio Urbano. Barcelona: [s.1.], 1975.

FANGER, O.; TOFUM, J. Extension of the PMV Model to No Air-Conditioned Buildings in Warm Climates. Energy and Buildings, v. 34, n. 6, p. 533-536, jul. 2002.

GIVONI, B. Climate Considerations in Building and Urban Design. New York: John Wiley and Sons, 1998.

GONÇALVES, W. B. Estudo de Índices de Conforto Térmico Avaliados com Base em População Universitária na Região Metropolitana de Belo Horizonte. 2000. Dissertação (Mestrado em Engenharia Mecânica) Escola de Engenharia, Universidade Federal de Minas Gerais, Belo Horizonte, 2000.

HUMPHREYS, M. Outdoor Temperatures and Comfort Indoors. Building Research \& Information, v. 6, n. 2, p. 92, 1978. 
INTERNATIONAL ORGANIZATION FOR

STANDARDIZATION. Standard 7730: moderate thermal environments: determination of the PMV and PPD indices and specification of the conditions for thermal comfort. Genebra, 1994.

LOURA, R. M. Procedimento de Identificação de Variáveis e Análise de sua Pertinência em Avaliações Termo-Energéticas de Edificações. 2006. Dissertação (Mestrado em Ciências e Técnicas Nucleares) - Escola de Engenharia, Universidade Federal de Minas Gerais, Belo Horizonte, 2006.

PEREIRA, I. M. Novas Metodologias para Simulação Energética de Edificações: estudo de caso. 2004. Dissertação (Mestrado em Ciências e Técnicas Nucleares) - Escola de Engenharia, Universidade Federal de Minas Gerias, Belo Horizonte, 2004.
PEREIRA, I. M. SOUZA, R. V. G. Proteção Solar em Edificações Residenciais e Comerciais: desenvolvimento de metodologia. In: ENCONTRO NACIONAL DE CONFORTO NO AMBIENTE CONSTRUÍDO, 12., 2008, Fortaleza. ANTAC: Anais... Fortaleza: Antac, 2008. p. 2149-2150.

NICOL, J. F. Adaptive Thermal Comfort Standards in the Hot-Humid Tropics. Energy and Buildings, v. 36, n. 7, p. 628-637, jul. 2004.

NICOL, J. F.; HUMPHREYS, M. A. Adaptive Thermal Comfort and Sustainable Thermal Standards for Buildings. Energy and Buildings, v. 34, n. 6, p. 563-572, jul. 2002.

XAVIER, A. A. P. Condições de Conforto Térmico para Estudantes de $2^{\circ}$ Grau na Região de Florianópolis. 1999. Dissertação (Mestrado em Engenharia Civil) - Universidade Federal de Santa Catarina, Florianópolis, 1999. 